\title{
El género Ficus (Moraceae) en la PROVINCIA BIOGEOGRÁFICA de la Depresión del Balsas, MÉXICo
}

\author{
Nahú González-Castañeda', Guadalupe Cornejo-Tenorio y Guillermo Ibarra-Manríquez \\ Centro de Investigaciones en Ecosistemas, Universidad Nacional Autónoma de México \\ 1Autor para la correspondencia: nahu@oikos.unam.mx
}

\begin{abstract}
Resumen: Con base en colectas de campo, revisión de literatura florística y taxonómica, así como en la revisión de ejemplares depositados en diversos herbarios, se registraron 11 especies de Ficus (Moraceae) en la Provincia Biogeográfica de la Depresión del Balsas. Las especies registradas pertenecen a los subgéneros Pharmacosycea (F. insipida y F. maxima) y Urostigma (F. citrifolia, F. cotinifolia, F. crocata, F. membranacea, F. obtusifolia, F. pertusa, F. petiolaris, F. pringlei y F. velutina), y en conjunto representan cerca del $50 \%$ del total reconocido para México, con dos taxones endémicos al país (F. petiolaris y $F$. pringlei). Los miembros de este género se distribuyen preferentemente en el bosque tropical caducifolio, entre los 800 y $1,600 \mathrm{~m}$ s.n.m. El trabajo contiene una clave de identificación y descripciones de cada especie que incluyen sinónimia, nombres comunes, distribución geográfica e imágenes que ilustran caracteres diagnósticos.
\end{abstract}

Palabras clave: Amate, bosque tropical caducifolio, higuera, matapalo.

\begin{abstract}
Based on field work, taxonomic and floristic literature, and herbarium specimens, eleven species of Ficus (Moraceae) in the Balsas Basin Biogeographic Province, Mexico, were recognized. These species belong to subgenera Pharmacosycea $(F$. insipida and F. maxima) and Urostigma (F. citrifolia, F. cotinifolia, F. crocata, F. membranacea, F. obtusifolia, F. pertusa, F. petiolaris, F. pringlei and F. velutina), and comprise ca. 50\% of the total species recorded in Mexico. Ficus petiolaris and F. pringlei are endemic to this country. Tropical deciduous forest is the most frequent vegetation type were these species can be found, mainly between 800 and 1,600 m. Descriptions, images, synonyms, and identification key are provided for each species.
\end{abstract}

Keywords: Amate, higuera, matapalo, tropical deciduous forest.

$\boldsymbol{F}_{\mathrm{c} u}$ cus (Moraceae) es considerado un taxón monofilético, cuya antigüedad se ha estimado entre 80 y 90 millones de años (Datwyler y Weiblen, 2004) y cuya característica más distintiva es que sus diminutas flores y frutos se disponen dentro de la superficie interna de un receptáculo (sicono o higo) casi totalmente cerrado, excepto por un orificio pequeño y apical denominado ostíolo. A nivel mundial se calcula que existen 750 especies con distribución pantropical y 140 especies en América (Berg, 1989). De acuerdo con este último autor, el género está representado por cuatro subgéneros en todo el mundo: Ficus L., Sycomorus (Gasp.) Miq., Pharmacosycea (Miq.) Miq. y Urostigma (Gasp.) Miq., con 350, 13, 75 y 280 especies, respectivamente. En el continente americano se distribuyen únicamente los dos últimos subgéneros, representados por las secciones Pharmacosycea Corner y Americana Miq., respectivamente (Berg, 1989, 2001; Ibarra-Manríquez, 1991).
La biología de los sistemas reproductivos de Ficus es de especial interés debido al mutualismo obligatorio con las avispas de la familia Agaonidae, donde éstas requieren de las flores pistiladas del sicono para reproducirse, y a su vez, las especies de Ficus dependen de las avispas para su polinización (Janzen, 1979; Ibarra-Manríquez, 1991; Ibarra-Manríquez y Wendt, 1992; Harrison, 2005). Debido a que en esta interacción las avispas sólo sobreviven por un corto periodo fuera de los higos (Smith y Bronstein, 1996; Harrison, 2005), las especies de Ficus deben producir higos durante todo el año para mantener sus poblaciones. Esta disponibilidad, permite que alimente al menos a 1,274 especies de aves y mamíferos en el mundo (Shanahan et al., 2001), funcionando como un recurso clave, particularmente en temporadas de escasez de frutos (Lambert y Marshall, 1991; Terborgh, 1992). Por lo anterior, se le considera como uno de los géneros de plantas más importantes para el manteni- 
miento de frugívoros tropicales (Janzen, 1979; Shanahan et al., 2001).

Debido a su alta diversidad y a la complejidad para separar con claridad las especies de Ficus, los estudios florísticos realizados en México se han definido con base en divisiones políticas (Standley, 1917, 1922; Ibarra-Manríquez y Wendt, 1992; Quintana-Cardoza y Carvajal, 2001; PiedraMalagón et al. 2006; Carvajal, 2007; Durán-Ramírez et al., 2010). A pesar de que este enfoque es válido, es importante considerar que los seres vivos no se distribuyen sobre áreas definidas artificialmente. En este sentido, una provincia biogeográfica ofrece límites naturales para el estudio de los organismos que la componen, permitiendo hacer análisis más detallados sobre su distribución y endemismo. Sin embargo, la regionalización biogeográfica de un país megadiverso como México es complicada, pues el número y extensión de las provincias puede diferir de acuerdo a los grupos que se analicen (e. g. Rzedowski, 1978; Morrone et al., 2002). Una de las provincias mejor consensuadas es la Provincia Biogeográfica de la Depresión del Balsas (PBDB), ya que diversos autores la reconocen con ligeras variantes de extensión o de nombre, tomando como base criterios florísticos, faunísticos y/o morfotectónicos (Rzedowski, 1978; Ferrusquía-Villafranca, 1992; Ramírez-Pulido y CastroCampillo, 1992, CONABIO, 1997; Escalante-Pliego et al., 1998, Espinosa-Organista et al., 2000; Morrone et al., 2002; Morrone, 2005).

Fernández-Nava et al. (1998) enlistan 13 especies nativas de Ficus y una cultivada, originaria del SE asiático ( $F$. elastica Roxb.) para la PBDB. No obstante, de acuerdo con la literatura especializada y los ejemplares de herbarios que se han colectado en el área, las especies que se enumeran en este estudio no son totalmente correctas. Todos los trabajos florísticos que incluyen especies que se encuentran en la PBDB contienen descripciones (morfología, distribución geográfica, nombres comunes, usos) y claves de identificación. Específicamente, consultando el trabajo de Standley $(1917,1922)$, en su tratamiento sobre 41 especies mexicanas y centroamericanas, se citan cinco especies en la provincia: F. cotinifolia Kunth, F. mexicana (Miq.) Miq., F. padifolia Kunth, F. petiolaris Kunth, F. segoviae Miq. Quintana-Cardoza y Carvajal (2001) describen 14 especies de Ficus en Jalisco y para la porción del estado que corresponde a la PBDB mencionan a F. glycicarpa (Miq.) Miq., F. goldmanii Standl., F. insipida Willd. y F. maxima Mill. Piedra-Malagón et al. (2006) citan ocho especies para Morelos, con dos nuevos registros (F. trigonata L. y Ficus sp.) y por primera vez para un estudio de este tipo, incluyen fotografías en fresco de las hojas y siconos de cada especie. Finalmente, Durán-Ramírez et al. (2010), en su tratamiento del género para el estado de Guerrero, documentan la presencia de $F$. citrifolia Mill. y F. crocata (Miq.) Miq., aunque esta última especie fue descrita por Piedra-Malagón et al. (2006) como F. trigonata. Si se consideran los taxones mencionados con anterioridad y se revisa el trabajo de Fernández-Nava et al. (1998), aun faltaría mencionar a F. kellermanii Standl. y $F$. lapathifolia (Liebm.) Miq. Esta última especie es incluida en el estudio de Durán-Ramírez et al. (2010), pero su distribución no coincide con los límites de la PBDB.

Considerando la importancia florística y ecológica de los miembros del género Ficus y la complejidad taxonómica para delimitarlos, el presente trabajo tiene como objetivos básicos: 1) facilitar la determinación de las especies de la Provincia Biogeográfica de la Depresión del Balsas, con base en una clave dicotómica, la cual se complementa con descripciones y fotografías que ilustran caracteres diagnósticos (hábito, yema foliar, hojas y siconos) y 2) discutir la problemática taxonómica de las especies.

\section{Materiales y Métodos}

Zona de estudio. Está ubicada en la parte centro sur de México e incluye porciones de los estados de Guerrero, Jalisco, México, Michoacán, Morelos, Oaxaca y Puebla, con una cota altitudinal que no sobrepasa los 2,000 m s.n.m. (Morrone et al., 2002; Morrone, 2005).

Todo el territorio de la PBDB se encuentra incluido en la cuenca hidrológica del río Balsas, la cual se originó en el Cretácico Inferior como una prolongación de la Gran Depresión del Golfo de California, debido a la convergencia entre las placas de Cocos y Americana (Toledo, 2003). Según los datos de García (2004), el clima predominante (38.2\% de las 204 estaciones climáticas existentes) es cálido subhúmedo (Aw), que se distribuye entre los 50 y 1,634 m s.n.m. El segundo tipo climático en importancia (27\%) es el semicálido subhúmedo $(\mathrm{A}(\mathrm{C}) \mathrm{w}$ y $(\mathrm{A}) \mathrm{C}(\mathrm{w}))$ que se localiza entre los 550 y 1,969 m s.n.m. El tercer tipo climático $(24.5 \%)$ es el semiárido $\left(\mathrm{BS}_{0}\right.$ y $\left.\mathrm{BS}_{1}\right)$, que ha sido registrado principalmente en la porción occidental de la cuenca entre los 80 y 2,000 m, debido al efecto de sombra orográfica provocado por las cordilleras de la Sierra Madre del Sur, que detienen la poca humedad proveniente del Océano Pacífico (TrejoVázquez, 1999). Finalmente, el clima templado subhúmedo $(\mathrm{C}(\mathrm{w}))$ tiene la menor representación (7.4\%) y se distribuye de 1,580 a 2,000 $\mathrm{m}$.

En la zona predominan los bosques tropicales secos y pastizales (Morrone, 2005). Rzedowski (1978) distingue para los primeros el bosque tropical caducifolio y el bosque tropical subcaducifolio. En la cuenca del Balsas también se han mencionado otros tipos de vegetación (Rzedowski, 1978; Fernández-Nava et al., 1998): bosque de coníferas, bosque de Quercus, matorral xerófilo y bosque mesófilo de montaña. Descripciones detalladas sobre climas y suelos donde se localizan estos tipos de vegetación, así como descripciones sobre su fisonomía pueden ser consultadas en Rzedowski (1978) y Fernández-Nava et al. (1998). En esta última contribución se registran 4,442 especies de plantas vasculares, pertenecientes a 202 familias. Rodríguez-Jimé- 
nez et al. (2005) indican que un total de 337 (7.6\%) especies son endémicas a la cuenca. Los géneros endémicos o cuasi endémicos son (Rzedowski, 1978; Diego-Pérez y Calderón, 2004; Sousa, 2005; Arias y Terrazas, 2008; Schilling, 2008): Backebergia (Cactaceae), Heteroflorum (Fabaceae), Lexarzanthe (Brassicaceae), Paneroa (Asteraceae) y $\times$ Pachebergia (Cactaceae). El género Bursera (Burseraceae) tiene su centro de diversificación en la zona con 49 especies, de las cuales 20 son endémicas (Rzedowski et al., 2004).

Elaboración de las descripciones. Con base en la revisión de 859 ejemplares en 15 herbarios (CH, CICY, CIMI, EBUM, ENCB, F, FCME, HUAP, HUMO, IEB, INIF, MEXU, MO, XAL y ZEA) y ejemplares colectados en campo, se elaboró una clave de identificación, descripciones y fotografías para cada una de las especies reconocidas en el presente trabajo. Se generaron mapas de distribución tomando como base las cartas de INEGI (1990) y CONABIO (1997). Los datos de distribución provienen de ejemplares de herbario, de colectas en campo y de literatura especializada (e. g. Vázquez-Ávila, 1981; Berg y Villavicencio, 2004; Serrato et al., 2004). La sinonimia únicamente incluye los nombres de especies utilizados en la literatura florística más relevante de la PBDB (Standley, 1917; Guízar-Nolazco y SánchezVelez, 1991; Fernández-Nava et al., 1998; Quintana-Cardoza y Carvajal, 2001; Serrato et al., 2004; Piedra-Malagón et al., 2006; Cué-Bär et al., 2006; Durán-Ramírez et al., 2010) y en ejemplares de herbario de la zona de estudio, con base en las decisiones taxonómicas de Berg y Simonis (1981), Ibarra-Manríquez y Wendt (1992), Berg y Villavicencio (2004), Berg $(2006,2007)$ y Piedra-Malagón et al. (en prensa). Debido al numeroso material incluido en el estudio, para cada especie se cita sólo un ejemplar por cada uno de los estados que conforman la PBDB. Los ejemplares adicionales examinados se enlistan en el Apéndice. Los términos botánicos utilizados en las descripciones fueron cotejados con Moreno (1984), excepto para el caso de la nervación, en el que se utilizó la obra de Stearn (1983). La coloración de las estructuras en seco sólo se resalta en aquellos casos donde es distintiva para la especie.

\section{Resultados y Discusión}

En la PBDB se registraron 11 especies de Ficus, dos pertenecientes al subgénero Pharmacosycea (F. insipida y $F$. maxima) y nueve del subgénero Urostigma $(F$. citrifolia, F. cotinifolia, F. crocata, F. membranacea, F. obtusifolia, F. pertusa, F. petiolaris, F. pringlei y F. velutina), lo que representa el $50 \%$ de las especies registradas para México (Serrato et al., 2004).

La distribución geográfica de las especies de Ficus en la PBDB se muestra en las figuras 1-3. La mayor cantidad de especies se distribuye en el bosque tropical caducifolio, el bosque tropical subcaducifolio y el bosque de galería. En los siguientes tipos de vegetación están representadas de dos a cinco especies: bosque de Quercus, matorral xerófilo, bosque de Pinus-Quercus, bosque de Pinus y bosque mesófilo de montaña. Las especies del género se distribuyen preferentemente entre los 800 y 1,600 m s.n.m., con límites mínimos y máximos de 250 y 2,200 m, respectivamente.

Es importante considerar que debido a la variación en caracteres diagnósticos de algunas especies de Ficus y a las controversias en su circunscripción $(e . g$. Berg y Simonis. 1981; Ibarra-Manríquez y Wendt, 1992; Quintana-Cardoza y Carvajal, 2001; Piedra-Malagón et al. 2006; Berg, 2007; Carvajal, 2007), se sugiere que $F$. cotinifolia, $F$. crocata, $F$. insipida, F. pertusa y F. velutina sean estudiados taxonómicamente con mayor detalle incluyendo toda su área de distribución (Centro y/o Sudamérica). Otro enfoque de investigación pendiente corresponde a la biología reproductiva de las avispas Agaonidae y de las especies de Ficus en México, ya que sólo se han estudiado tres especies (F. insipida, F. pertusa y $F$. petiolaris) en una localidad al norte del país (Smith y Bronstein, 1996), a pesar de la importancia de documentar esta relación mutualista para obtener una comprensión integral sobre la taxonomía de ambos interactuantes (Berg, 1989, 2001; Ibarra-Manríquez y Wendt, 1992; Harrison, 2005).

\section{Clave de identificación}

1. Siconos solitarios en la axila de las hojas; ostíolo sin brácteas oclusivas; siconos inmaduros sin involucro caliptriforme; árboles de crecimiento independiente (terrestres); raíces aéreas ausentes ................... 2 (subgénero Pharmacosycea) 1. Siconos geminados en la axila de las hojas; ostíolo con brácteas oclusivas; siconos inmaduros con involucro caliptriforme; árboles rupícolas o hemiepífitos; raíces aéreas usualmente presentes ................... 3 (subgénero Urostigma) 2. Yema foliar menor a $2.3 \mathrm{~cm}$ de largo; epidermis de entrenudos y pecíolos exfoliándose en pequeñas escamas irregulares; lámina foliar con 7 a 14 pares de nervios secundarios; haz y envés comúnmente escabrosos; sicono escabroso; ostíolo aplanado a ligeramente hundido ................ F. maxima

2. Yema foliar mayor a $2.3 \mathrm{~cm}$ de largo; epidermis de entrenudos y pecíolos sin exfoliarse; lámina foliar con 11 a 21 pares de nervios secundarios; haz y envés comúnmente lisos; sicono liso; ostíolo tubular .......................... F. insipida 3. Lámina foliar cordiforme; envés con una agrupación de tricomas blancos en las axilas de los nervios basales; corteza amarilla F. petiolaris 3. Lámina foliar no cordiforme; envés sin tricomas agrupados en las axilas de los nervios basales; corteza gris o parda

4. Lámina foliar glabra .......................................................... 5

4. Lámina foliar indumentada por el haz y/o por el envés

5. Pecíolo glabro, de la mitad o más de longitud respecto al largo de la lámina; sicono sésil; brácteas basales pilosas por 
la cara interna, puberulentas por la cara externa

F. membranacea

5. Pecíolo glabro o puberulento, menos de la mitad de longitud respecto al largo de la lámina; sicono pedunculado; brácteas basales glabras o puberulentas por las dos caras

6. Pecíolo glabro; lámina foliar obovada; brácteas basales robustas, cubriendo de una cuarta parte a la mitad del sicono F. obtusifolia

6. Pecíolo glabro a puberulento; lámina foliar nunca obovada; brácteas basales diminutas, cubriendo menos de una cuarta parte del sicono 7 7. Lámina foliar elíptico-oblonga; ápice obtuso a redondeado; siconos grandes de 1-2.2 cm de largo; ostíolo anillado; exudado blanco cambiando a rosado al oxidarse

F. crocata

7. Lámina foliar elíptico-lanceolada, ovada u oblonga; ápice acuminado, apiculado o agudo; siconos pequeños de 0.5-1.7 cm de largo; ostíolo crateriforme o aplanado; exudado blanco o grisáceo

8. Lámina foliar elíptico-lanceolada a ovada; ápice agudo o apiculado; ostíolo crateriforme de 0.14-0.28 cm; exudado blanco F. pertusa

8. Lámina foliar oblonga, a veces elíptica; ápice acuminado; ostíolo aplanado de 0.25-0.36 cm; exudado grisáceo, casi transparente F. citrifolia

9. Sicono menor a $1 \mathrm{~cm}$ de largo, sésil o pedunculado; ostíolo aplanado o cónico; exudado blanco, sin cambio de color al oxidarse 10

9. Sicono mayor a $1 \mathrm{~cm}$ de largo, pedunculado; ostíolo anillado; exudado blanco cambiando de color al oxidarse ........ 11 10. Estípulas lanosas en la cara externa y glabras en la interna; base foliar cuneada a redondeada; sicono glabro sésil; brácteas basales piloso canescentes por la cara interna y puberulentas por la cara externa; ostíolo aplanado

F. cotinifolia

10. Estípulas pubescentes o puberulentas en la cara externa e indumentadas sólo en la base de la cara interna; base foliar subcordada; sicono indumentado y sésil o pedunculado; brácteas basales pilosas a ocasionalmente glabradas por las dos caras; ostíolo cónico ..................................... F. pringlei 11. Estípulas ciliadas, con indumento ferrugíneo abundante; lámina foliar elíptica a elíptico-ovada, a veces elíptica-obovada; haz opaco; envés aterciopelado F. velutina 11. Estípulas no ciliadas, con indumento blanco escaso; lámina foliar elíptico-oblonga; haz lustroso; envés liso .....

F. crocata

Ficus citrifolia Mill., Gard. Dict. ed. 8. 1768. (Figura 4A y 5A). F. laevigata Vahl, Enum. Pl. 2: 183. 1805. F. lentiginosa Vahl, Enum. Pl. 2: 183. 1805.

Árbol rupícola, de 3 a $25 \mathrm{~m}$ de alto; contrafuertes definidos; corteza lisa, gris; raíces aéreas presentes, numerosas; exudado grisáceo, casi transparente. Yema foliar 8-12 $\times 2.5-3 \mathrm{~mm}$, glabra, pardo oscura a negra en fresco, negra en seco; estípulas 8-12 $\times 4-6 \mathrm{~mm}$, glabras, pardo oscuras a negras en fresco, negras en seco. Entrenudos 4-36 × 3-4 $\mathrm{mm}$, glabros, pardo verdosos a grises en fresco, lisos. Pecíolo 26-43 × 1-2 mm, glabro, verde amarillento en fresco, acanalado; lámina foliar 9.9-11.5 × 5.7-7.9 cm, oblonga, a veces elíptica; base truncada a obtusa; ápice acuminado; haz glabro, verde oscuro en fresco, liso, lustroso; envés glabro, verde pálido en fresco, liso, opaco, con 10-14 pares de nervios secundarios. Sicono 7-13 × 11-14 mm, cortamente turbinado, glabro, verde pálido con máculas amarillo pálidas en fresco; pedúnculo 4-6 × 1-1.4 mm, glabro; brácteas basales $2 \times 3 \mathrm{~mm}$, glabras, persistentes, cubriendo menos de la cuarta parte del higo; ostíolo 2.5-3.6 $\times 2.5-3.5 \mathrm{~mm}$, aplanado o crateriforme, con dos a tres brácteas oclusivas, visibles al microscopio, glabras; flores blancas a rosadas en fresco.

En América se distribuye desde los Estados Unidos de América (Florida), México, Las Antillas y a través de Centroamérica hasta el norte de Argentina. En México se ha colectado por la vertiente del Pacífico (Nayarit a Chiapas) y del Atlántico (Campeche, Quintana Roo y Yucatán). En la región de estudio sólo se ha registrado en dos localidades (Figura 1A) en bosque de galería, a 290 y 580 m s.n.m.

Nombres comunes y usos: camichín.

Esta especie se caracteriza por su hábito rupícola, exudado grisáceo casi transparente, lámina oblonga, con ambas superficies glabras, base truncada, ápice acuminado y sicono glabro. En el área de estudio no existen especies con las que se pueda confundir. Sin embargo, F. citrifolia constituye un complejo de especies (Berg y Simonis, 1981; Berg, 1989) con una sinonimia extensa (Berg y Villavicencio, 2004), que se reduce a seis formas en toda su área de distribución (Berg, 2007), aunque en México se presenta únicamente la forma citrifolia.

Material examinado. Guerrero: Mpio. Coahuayutla de José María Izazaga: La Vainilla, $2.77 \mathrm{~km}$ al N, J. Calónico 15161 (FCME, MEXU). Michoacán: Mpio. Apatzingán: rancho El Cantor, $10 \mathrm{~km}$ al SO de Apatzingán, X. Madrigal s. $n$. (EBUM).

Ficus cotinifolia Kunth, Nov. Gen. Sp. (quarto ed.) 2: 49. 1817. (Figura 4B y 5B). Urostigma cotinifolium (Kunth) Miq., Nov. Gen. Sp. (quarto ed.) 2: 49. 1817.

Árbol estrangulador, hemiepífito o rupícola, de 4 a $30 \mathrm{~m}$ de alto; contrafuertes definidos; corteza lisa, gris clara; raíces aéreas anastomosantes; exudado blanco, abundante en ramas juveniles. Yema foliar 4-7 (-13) × 2-4 (-5) mm, con las hojas juveniles lanosas por las dos caras, el indumento blanco a blanco amarillento en fresco y en seco; estípulas (4-) 5-7 (-13) $\times 3-7 \mathrm{~mm}$, lanosas por la cara externa, glabras por la cara interna, el indumento blanco a blanco amarillento en fresco y en seco. Entrenudos (4) 10-20 (-56) × (2-) 3-4 $(-6) \mathrm{mm}$, pubescentes hacia la yema, glabrescentes hacia la ramilla o completamente glabros, pardo grisáceos en fresco, 
Ficus en la Provincia Biogeográfica del Balsas

Cuadro 1. Caracteres diagnósticos para diferenciar F. cotinifolia, F. pringlei y F. membranacea.

\begin{tabular}{|c|c|c|c|}
\hline Caracteres & Ficus cotinifolia & Ficus pringlei & Ficus membranacea \\
\hline Yema foliar & Lanosa & Pubescente a puberulenta & Estrigosa \\
\hline Longitud pecíolo & $0.6-5.7 \mathrm{~cm}$ & $0.5-2 \mathrm{~cm}$ & $4.2-15.6 \mathrm{~cm}$ \\
\hline Longitud lámina & $3.3-10.6 \mathrm{~cm}$ & $4.2-7.8 \mathrm{~cm}$ & $8-30 \mathrm{~cm}$ \\
\hline Base foliar & Cuneada a redondeada & Subcordada & $\begin{array}{l}\text { Obtusa, redondeada, truncada o } \\
\text { subcordada }\end{array}$ \\
\hline Haz y envés & Indumentados & Indumentados & Glabros \\
\hline Venación terciaria & No conspicua & Conspicua & No conspicua \\
\hline Sicono & Sésil, glabro & Subsésil, indumentado & Sésil, indumentado \\
\hline Longitud sicono & $0.4-1 \mathrm{~cm}$ & $0.7-0.9 \mathrm{~cm}$ & $0.8-1.2 \mathrm{~cm}$ \\
\hline Ostíolo & Aplanado & Cónico & Aplanado \\
\hline Distribución en México & Centro, Vertiente Atlántica y Pacífica & Vertiente Pacífica & Vertiente Pacífica \\
\hline
\end{tabular}

ligeramente anillados, estriados. Pecíolo (7-) 18-25 (-57) $\times 1-2 \mathrm{~mm}$, indumentado, verde pálido a verde amarillento en fresco, acanalado; lámina foliar (3.3-) 5.7-8.1 (-10.6) $\times$ (1.8-) 3.8-5.1 (-7.6) cm, obovada, oblonga o casi orbicular, a veces anchamente elíptica; base cuneada a redondeada, en ocasiones truncada; ápice redondeado a obtuso, raramente agudo; haz puberulento a glabro, verde oscuro en fresco, liso; envés pubescente a raramente glabrado, verde pálido en fresco, aterciopelado a liso, venas secundarias de (4-) 5-6 (-8) pares, el primer par suele llegar a un tercio o hasta la mitad de la lámina. Sicono (4-) 6-7 (-10) × (5-) 7-8 (-11) $\mathrm{mm}$, obloide a globoso, glabro a raramente indumentado, verde, rojo oscuro o negro con máculas pardas en fresco, sésil; el par de siconos jóvenes protegidos por un involucro caliptriforme, puberulento en la cara externa, glabro en la cara interna; brácteas basales 2-7 × 2-7 $\mathrm{mm}$, reniformes, puberulentas por la cara externa, piloso canescentes por la cara interna, persistentes, cubriendo hasta la tercera parte del sicono, concrescentes; ostíolo 2-3 × 2-3 mm, aplanado, en ocasiones ligeramente prominente, comúnmente con tres brácteas oclusivas visibles a simple vista; flores blancas en fresco.

Se trata de una especie ampliamente colectada desde el norte de México hasta Costa Rica. Para la zona de estudio sólo falta colectarla en Jalisco (Figura 1A). Los árboles de este taxón habitan preferentemente en el bosque tropical caducifolio, el bosque tropical subcaducifolio y el bosque de galería, con una menor frecuencia en el bosque de Quercus; se ha colectado en un intervalo altitudinal de 250 a $1,850 \mathrm{~m}$ s.n.m.

Nombres comunes y usos: amaiskitle, amaiskitl, amate, amate blanco, amate de zorra, amate prieto, amezquite, amezquite blanco, cabrigo, camichín, camichina, camuchín, camuchina, ceiba negra, higo, higo de zorro, saiba blanca, saiba guicha, texcalamate, tlalanatl, tlaligo, zalate; los frutos son comestibles y la madera se utiliza para postes de potreros.

Ficus cotinifolia se caracteriza por sus yemas foliares lanosas, con el indumento blanco, ostíolo aplanado, brácteas basales persistentes, pilosas por la cara interna y puberulentas por la externa y por su primer par de venas secundarias que se extienden desde la base hasta un tercio o la mitad de la longitud de la lámina. Esta especie puede ser confundida con $F$. pringlei y F. membranacea (Cuadro 1). Ficus cotinifolia conforma un complejo taxonómico que requiere una evaluación de sus poblaciones en toda su área de distribución (Carvajal y Peña-Pinela, 1997; Piedra-Malagón et al., 2006).

Material examinado. Estado de México: Mpio. Ixtapan de la Sal: Ixtapan de la Sal, E. Matuda 27079 (MEXU). Guerrero: Mpio. Alpoyeca: $1.5 \mathrm{~km}$ al E de Tecoyo, cañada Tecuane, J. Calónico 1654 (FCME, HUAP, MEXU). Michoacán: Mpio. Apatzingán: 4 miles $\mathrm{W}$ of Apatzingan, $W$. M. C. Leavenworth 1386 (F, MO). Morelos: Mpio. Tlaquiltenango: cerro Grande, $1 \mathrm{~km}$ al E de Jojutla, J. Rzedowski 18684 (ENCB, INIF). Oaxaca: Mpio. Santos Reyes Tepejillo: $3 \mathrm{~km}$ al N de Santos Reyes Tepejillo, senda para Corral de Piedra, J. I. Calzada 22579 (MEXU). Puebla: Mpio. Acatlán: 13 millas al O de Acatlán sobre la carretera 190, D. Dunn 23064 (ENCB, INIF, MO).

Ficus crocata (Miq.) Miq., Ann. Mus. Bot. Lugduno-Batavum 3: 297. 1867. (Figura 4C y 5C). F. goldmanii Standl., Contr. U.S. Natl. Herb. 20(1): 32. 1917. F. hemsleyana Standl., Contr. U.S. Natl. Herb. 20(1): 29. 1917.

Árbol hemiepífito, raramente rupícola, de 4 a $30 \mathrm{~m}$ de alto; contrafuertes definidos; corteza lisa, castaña a pardogrisácea; con raíces aéreas; exudado blanco que adquiere un tono rosado al oxidarse, abundante en las ramas juveniles. Yema foliar (7-) 12-17 (-28) $\times 2-4 \mathrm{~mm}$, con indumento blanco, verde en fresco; estípulas (7-) 12-17 (-28) × 4-7 $\mathrm{mm}$, indumentadas por la cara externa, glabras por la cara interna, verdes en fresco. Entrenudos (-5) 10-20 (-47) $\times$ (3-) 5-6 (-9) $\mathrm{mm}$, puberulentos a ocasionalmente glabros, pardos en fresco, lisos, agrietados. Pecíolo (9-) 22-28 (-42) $\times(1-) 2(-3) \mathrm{mm}$, indumentado a glabro, verde pálido en fresco, siempre más oscuro que el nervio principal en seco, acanalado en el haz; lámina foliar (4.5-) 10.4-13.2 (-18.4) $\times(3-)$ 4.8-5.9 (-7.5) cm, elíptico-oblonga; base cuneada o 

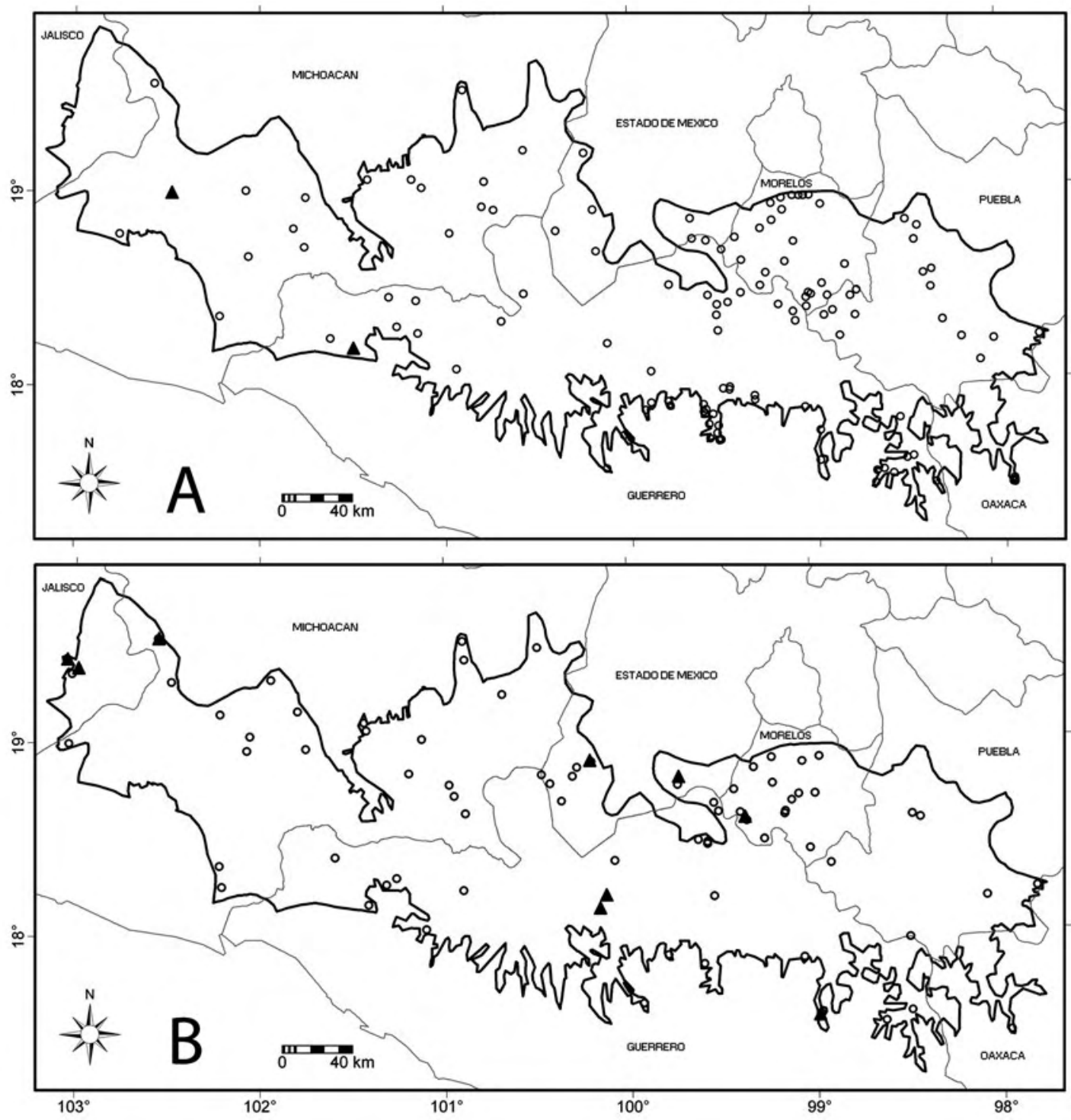

Figura 1. Distribución geográfica de las especies: A) F. citrifolia $(\mathbf{\Delta}), F$. cotinifolia $(\bigcirc)$; B) F. crocata $(\bigcirc), F$. maxima $(\mathbf{\Delta})$ en el área de estudio.

redondeada, a veces ligeramente subcordada; ápice obtuso a redondeado; haz glabro a raramente glabrado, verde oscuro en fresco, liso, lustroso; envés glabro a puberulento, verde pálido en fresco, áspero o liso, opaco, con (6-) 8-12 (-13) pares de nervios secundarios. Sicono (10-) 15-16 (-22) $\times(9-)$ 15-16 (-23) mm, globoso a ligeramente obloide, puberulento a raramente glabro, verde con máculas amarillas en fresco, las máculas más agregadas alrededor del ostíolo y glabras o glabradas; el par de siconos jóvenes presentan un involucro caliptriforme, membranáceo y puberulento en la cara externa que al caer deja ver los dos siconos aun cubiertos por las brácteas basales; pedúnculo (5-) 9-10 (-23) × (1-) $2(-3) \mathrm{mm}$, puberulento; brácteas basales $5-7 \times 4-5 \mathrm{~mm}$, deltadas con el ápice redondeado a agudo, puberulentas en la cara externa, glabras por la cara interna, en ocasiones ci- lioladas, persistentes, a veces cubriendo hasta la cuarta parte del sicono, ocasionalmente concrescentes; ostíolo (2-) 3-4 $(-5) \times(2-) 3(-5) \mathrm{cm}$, a menudo rodeado por un anillo ligeramente prominente, con tres brácteas oclusivas visibles al microscopio, puberulentas; flores de color rosa pálido a blancas en fresco.

Especie de amplia distribución desde México y Las Antillas hasta Bolivia y Brasil. En la PBDB también está ampliamente distribuída (Figura 1B). Ficus crocata habita comúnmente en el bosque tropical caducifolio y en el bosque de galería y de manera más ocasional en el bosque tropical subcaducifolio, bosque de Pinus-Quercus, bosque de Quercus y matorral xerófilo; presenta un intervalo altitudinal amplio, desde 300 hasta $2,100 \mathrm{~m}$ s.n.m, pero se encuentra con mayor frecuencia entre 700 y $1,500 \mathrm{~m}$. 

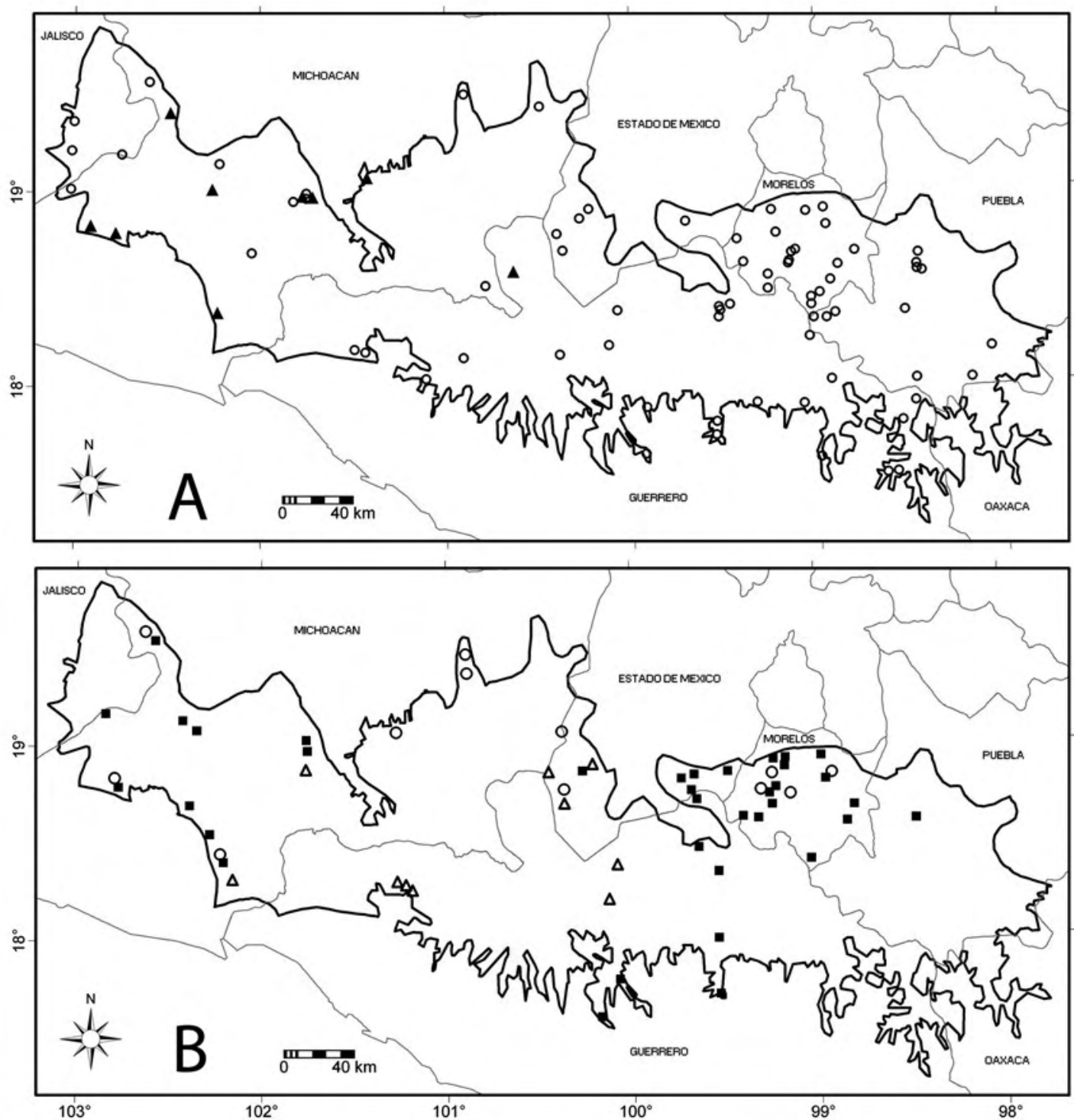

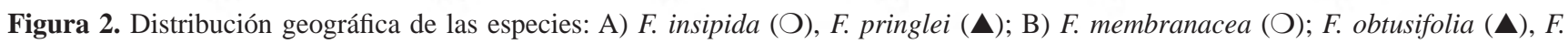
pertusa $(\mathbf{\square})$ en el área de estudio.

Nombres comunes y usos: amate, amate negro, amate prieto, ceiba, higuera prieta, higuerón, saiba, saiba negra, saiba prieta, zalate, ziranda; los frutos son comestibles, se utiliza como árbol de sombra, la madera para postes de potreros y combustible.

Esta especie se distingue por el haz glabro y lustroso, la lámina foliar elíptico-oblonga y el exudado que se vuelve rosado al oxidarse. Puede ser confundida con $F$. velutina (Cuadro 2) y se le ha determinado previamente como F. trigonata L. (Piedra-Malagón et al., 2006), una especie que se distribuye exclusivamente en el área de Las Antillas (Berg y Villavicencio, 2004). Sin embargo, Ficus crocata pertenece al complejo taxonómico F. trigonata sensu Berg y Simonis (1981), caracterizado por hojas medianas a largas, higos con pedúnculos cortos, con un anillo alrededor del ostíolo.
Material examinado. Estado de México: Mpio. Amatepec: cercanías de Amatepec, E. Matuda 29839 (MEXU). Guerrero: Mpio. Zirándaro: $2 \mathrm{~km}$ al $\mathrm{N}$ de Guayameo, J. C. Soto 4373 (IEB, MEXU). Jalisco: Mpio. Jilotlán de los Dolores: Cascalote, J. Rzedowski 1646 (ENCB, INIF, MEXU). Michoacán: Mpio. Apatzingán: La Majada, W. M. C. Leavenworth 1348 (F, MO). Morelos: Mpio. Tlaltizapán: $10 \mathrm{~km}$ by road E of Tlaltizapán, H. H. Iltis 3015 (MEXU, XAL). Oaxaca: Mpio. Santiago Chazumba: Cañada de Coyul, El Higo, E. Guízar 4400 (MEXU). Puebla: Mpio. Acatlán: Amatitlán de Azueta, F. A. Miranda 2102 (MEXU).

Ficus insipida Willd., Sp. Pl. 4(2): 1143. 1806. (Figura 4D y 5D). F. glabrata Kunth, Nov. Gen. Sp. (quarto ed.). 2: 47. 1817. F. mexicana (Miq.) Miq., Ann. Mus. Bot. Lugduno- 


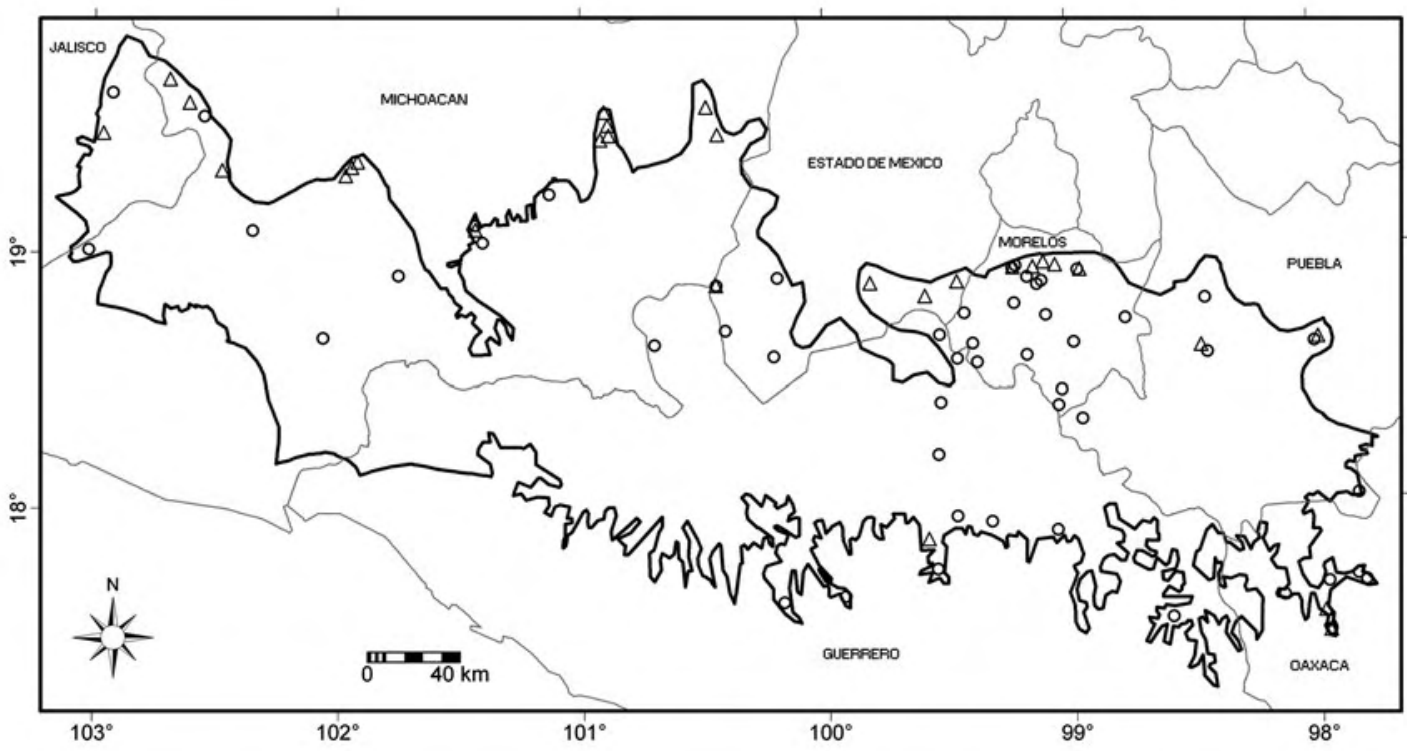

Figura 3. Distribución geográfica de $F$. petiolaris $(\bigcirc)$ y $F$. velutina $(\Delta)$ en el área de estudio.

Batavum. 3: 299. 1867. F. radulina S. Watson, Proc. Am. Acad. 26: 151. 1891. F. segoviae Miq., Ann. Mus. Bot. Lugduno-Batavum. 3: 300. 1867.

Árbol de 5 a $30 \mathrm{~m}$ de alto; con o sin contrafuertes; corteza lisa, gris clara; exudado blanco más abundante en las ramas que en la corteza. Yema foliar (27-) 48-55 (-94) $\times 4-5 \mathrm{~mm}$, glabra u ocasionalmente indumentada, verde en fresco; estípulas (27-) 48-55 (-94) $\times$ 6-9 mm, glabras a raramente indumentadas, verde pálido en fresco. Entrenudos (6-) 9-20 $(-5) \times(2-)$ 4-5 mm, pilosos a glabros, pardos, grises a verdes en fresco, estriados. Pecíolo (11-) 28-36 (-51) × (1-) 2- ($3) \mathrm{mm}$, glabro o a veces glabrado, verde en fresco, ligeramente acanalado; lámina foliar (8-) 12-15.7 (-25.9) × (2.8-) 4.1-5.3 (-8.7) cm, elíptico lanceolada a ligeramente ovada;

Cuadro 2. Caracteres diagnósticos para distinguir Ficus crocata y $F$. velutina.

\begin{tabular}{|c|c|c|}
\hline Caracteres & Ficus crocata & Ficus velutina \\
\hline Indumento yema foliar & Blanquecino & Ferrugíneo \\
\hline Estípula & No ciliada & Ciliada \\
\hline Entrenudo & Puberulento a glabro & Tomentoso a piloso \\
\hline Lámina foliar & Elíptico-oblonga & $\begin{array}{l}\text { Elíptica a elíptica- } \\
\text { ovada }\end{array}$ \\
\hline Haz & Glabro, lustroso & $\begin{array}{l}\text { Pilósulo a glabrado, } \\
\text { opaco }\end{array}$ \\
\hline Envés & Puberulento a glabro & $\begin{array}{l}\text { Puberulento a } \\
\text { tomentoso }\end{array}$ \\
\hline Venación terciaria & No conspicua & Conspicua \\
\hline Sicono & Puberulento a glabro & $\begin{array}{l}\text { Puberulento a } \\
\text { tomentoso }\end{array}$ \\
\hline Altitud (m s. n. m) & 700 a 1,500 & 1,500 a 2,000 \\
\hline
\end{tabular}

base atenuada a cuneada; ápice acuminado o apiculado; haz glabro, verde oscuro en fresco, liso, rara vez áspero; envés glabro a raramente puberulento, verde pálido en fresco, liso, rara vez áspero, con (11-) 15-16 (-21) pares de nervios secundarios. Sicono (12-) 16-18 (-29) × (10-) 15-17 (-28) $\mathrm{mm}$, umbonado a esferoide, glabro a indumentado, verde con máculas ovaladas amarillas en fresco, liso; pedúnculo (3-) 5-8 (-9) $\times 2(-4) \mathrm{mm}$, glabro a indumentado; brácteas basales diminutas de $2 \times 2 \mathrm{~mm}$, deltadas, glabras a raramente indumentadas en la cara externa, glabras en la cara interna, caedizas, dejando una cicatriz sobre el pedúnculo; ostíolo $2(-4) \times(1-)$ 2-3 mm, tubular; flores de color rosado en fresco.

Especie distribuida desde México y Las Antillas hasta Argentina. En la República Mexicana se le encuentra por la vertiente del Pacífico de Chihuahua a Chiapas y por la vertiente del Atlántico de Tamaulipas a Tabasco, mientras que en el centro del país se distribuye en los estados de México, Morelos, Puebla, Querétaro y San Luis Potosí. Con excepción de Oaxaca, se le ha colectado en el resto de las entidades de la PBDB (Figura 2A). Habita generalmente en el bosque de galería y bosque tropical caducifolio, con una menor frecuencia en el bosque tropical subcaducifolio, matorral xerófilo y bosque de Quercus; sus límites altitudinales van de 300 a 1,850 m s.n.m.

Nombres comunes y usos: amate, amate blanco, amate cabrigo, ceiba, higuera, higuera blanca, saiba blanca; se aprovecha como alimento y sombra para el ganado.

Esta especie se caracteriza por su yema terminal larga, pecíolos y siconos glabros, e interior del sicono fresco de color rosado y ha sido incorrectamente determinada como F. maxima (Cuadro 3) y F. yoponensis Desv., esta última especie sin ejemplares que respalden su presencia en el área 
Ficus en la Provincia Biogeográfica del Balsas

de estudio. Ficus insipida ha sido ubicada en la subsección Bergianae Carvajal \& Shabes, caracterizada por láminas lisas, epidermis del pecíolo persistente y estructuras florales de longitud uniforme en la antesis (Carvajal y Shabes, 1998; Berg, 2006).

Material examinado. Estado de México: Mpio. Tejupilco: $3 \mathrm{~km}$ al NO de Pinzanes, Tejupilco, F. González 5470 (MEXU). Guerrero: Mpio. Ahuacuotzingo: 4 km de Ahuacuotzingo rumbo a Ajuatetla, N. Diego 9471 (MEXU). Jalisco: Mpio. Jilotlán de los Dolores: aproximadamente 10 km sobre la brecha que va de Jilotlán a Tecalitlán, $M$. Cházaro 5626 (ENCB, IEB, XAL). Michoacán: Mpio. La Huacana: alrededores del Ejido Agua Blanca, G. Ibarra 5957 y 5965 (IEB, MEXU, MO). Morelos: Mpio. Tepalcingo: El Limón rumbo a Los Sabinos, F. Camacho 1739 (MEXU). Puebla: Mpio. Acatlán: Amatitlán de Azueta, F. A. Miranda 2040 (MEXU).

Ficus maxima Mill., Gard. Dict. ed. 8. 1768. (Figura 4E y 5E). F. glaucescens (Liebm.) Miq., Ann. Mus. Bot. Lugduno-Batavum. 3: 300. 1867. F. guadalajarana S. Watson, Proc. Amer. Acad. Arts. 26: 151. 1891. F. radula Humb. \& Bonpl. ex Willd., Sp. Pl. 4(2): 1144. 1806.

Árbol de 5 a $20 \mathrm{~m}$ de alto; contrafuertes definidos o no; corteza lisa, pardo grisácea a gris oscura; exudado blanco, abundante en las ramas jóvenes. Yema foliar (9-) 13-14 (17) $\times(2-)$ 3-4 (-6) mm, indumentada, verde en fresco; estípulas (9-) 13-14 (-17) $\times$ 4-8 mm, puberulentas hacia la base, glabrescentes hacia el ápice, con el indumento canoso, verdes en fresco. Entrenudos (5-) 12-22 (-38) × 3-4 (-6) $\mathrm{mm}$, pardo pálidos en fresco, puberulentos cuando jóvenes, posteriormente la epidermis se exfolia en pequeñas escamas con forma irregular y entonces son glabros. Pecíolo (7-) 14$23(-42) \times 2(-3) \mathrm{mm}$, pubescente a puberulento, epidermis exfoliante en pequeñas escamas irregulares y entonces glabro, pardo a verde en fresco, ligeramente acanalado; lámina foliar (8.9-) $12.3-15(-22.8) \times(3.6-) 5.7-7.3(-9.9) \mathrm{cm}$, elíptico ovada; base cuneada, a veces ligeramente obtusa; ápice agudo, en ocasiones cortamente apiculado, raramente redondeado; haz glabrado, verde oscuro en fresco, escabroso; envés pubescente, verde pálido en fresco, escabroso, con 7-14 pares de venas secundarias. Sicono (12-) 17-19 (-26) $\times(10-)$ 18-19 (-25) mm, esferoide a ligeramente obloide, umbilicado, pubescente, con el indumento canoso, verde oscuro a verde amarillento en fresco, escabroso, máculas ausentes o diminutas; pedúnculo (9-) 13-15 (-19) × 2 -3 mm, densamente pubescente, el indumento translúcido a canoso; brácteas basales diminutas de $1-2 \times 2-3 \mathrm{~mm}$, deltadas a irregulares, indumentadas a glabrescentes por la cara externa, glabras por la cara interna, persistentes, cubriendo menos de la octava parte del sicono; ostíolo 1-2 × 1-2 mm, aplanado a ligeramente hendido; flores de color rosado en fresco.

Ficus maxima presenta una distribución amplia, desde México y Las Antillas hasta Argentina. En México se le ha
Cuadro 3. Caracteres diagnósticos para diferenciar Ficus insipida y $F$. maxima.

\begin{tabular}{lll}
\hline Caracteres & Ficus insipida & Ficus maxima \\
\hline Longitud estípula & $2.7-9.4 \mathrm{~cm}$ & $0.9-1.7 \mathrm{~cm}$ \\
Pecíolo & Glabro, no exfoliante & Indumentado, exfoliante \\
Haz & Glabro, liso & Glabrado, escabroso \\
Envés & Liso & Escabroso \\
Venas secundarias & $11-21$ & $7-14$ \\
Sicono & Liso & Escabroso \\
Ostíolo & Tubular & Deprimido o aplanado \\
\hline
\end{tabular}

registrado por la vertiente del Pacífico (Sonora a Chiapas) y del Atlántico (Veracruz hasta la Península de Yucatán), y en el centro del país en los estados de México, Morelos, Puebla, Querétaro y San Luis Potosí. En la PBDB se ha encontrado en Guerrero, Jalisco, México, Michoacán y Morelos (Figura 1B), habitualmente en el bosque tropical subcaducifolio y el bosque de galería, con una menor frecuencia en el bosque tropical caducifolio y raramente en el bosque de Pinus-Quercus; esta especie se ubica entre 900 y 1,800 m s.n.m.

Nombres comunes y usos: amate, camuchín.

Un taxón que se caracteriza por sus pecíolos y entrenudos con la epidermis exfoliante en pequeñas escamas irregulares, envés de la hoja y sicono escabrosos, interior del sicono en fresco de color rosado y ostíolo diminuto, ligeramente hendido. En ocasiones se le ha determinado incorrectamente como F. insipida, situación que se aclara en el Cuadro 3. Ficus maxima ha sido incluida en la subsección Petenenses Carvajal \& Shabes, caracterizada por láminas foliares escabrosas, epidermis del pecíolo exfoliante y estructuras florales de longitud variable en la antesis (Carvajal y Shabes, 1998; Berg, 2006).

Material examinado. Estado de México: Mpio. Tejupilco: en el cerro de la Muñeca, E. Matuda 30523 (MEXU). Guerrero: Mpio. Arcelia: al E de Achotla, V. W. Steinmann 4879 (MEXU). Jalisco: Mpio. Jilotlán de los Dolores: 30 km al O de Jilotlán a Tecalitlán, rancho El Rayo, A. Flores 915 a (IEB, INIF, XAL). Michoacán: Mpio. Los Reyes: cerca del río y de la escalinata en la parte media y alta, Los Chorros del Varal, I. García 7427 (CIMI, IEB). Morelos: Mpio. Amacuzac: Calle Galeana, $2 \mathrm{~km}$ al E del zocalo de Amacuzac, E. M. Piedra 233 (XAL).

Ficus membranacea C. Wright, Anales Acad. Ci. Med. Habana 7: 514. 1870. (Figura 4F y 5F). F. jonesii Standl., Contr. U.S. Natl. Herb. 20(1): 31. 1917.

Árbol rupícola, raramente hemiepífito, de 4 a $25 \mathrm{~m}$ de alto; contrafuertes presentes; corteza lisa, gris clara a pardo grisácea; raíces aéreas anastomosantes, grises; exudado blanco a blanco amarillento. Yema foliar (8-) 13-18 (-44) $\times$ (3-) 5-6 mm, indumentada, verde clara en fresco; estípulas (8-) 13-18 (-44) $\times 7-8 \mathrm{~mm}$, ciliadas, estrigosas por la cara 
externa, el indumento amarillento más conspicuo hacia el centro de la estípula, glabras por la cara interna, verde claras en fresco. Entrenudos (6-) 8-20 (-29) $\times(2-)$ 4-6 mm, glabros a raramente indumentados, verdes a grises en fresco, estriados. Pecíolo (43-) 62-105 (-156) × (1-) 2 (-3) mm, glabro, verde amarillento en fresco, ligeramente acanalado; lámina foliar (8-) 9.8-18 (-30) × (4.4-) 6.5-10.5 (-18.5) cm, elíptico oblonga a elíptico circular, ovada a ocasionalmente obovada; base obtusa, redondeada, truncada o ligeramente cordada; ápice obtuso, redondeado o agudo, raramente apiculado; haz glabro, verde oscuro en fresco, liso; envés glabro, verde pálido en fresco, liso, con (5-) 6-8 (-11) pares de nervios secundarios. Sicono (9-) $10(-12) \times(10-)$ 11-13 $\mathrm{mm}$, obloide a esferoide, verde grisáceo a amarillo rojizo en fresco, pubescente, el indumento amarillento, sésil; máculas glabras a glabradas, pardo rojizas a negras en fresco; brácteas basales $4-8 \times 5-10 \mathrm{~mm}$, en ocasiones hendidas, irregulares a reniformes, el ápice redondeado, pubescentes por la cara externa, pilosas por la cara interna, el indumento amarillento, persistentes, en ocasiones cubriendo hasta la tercera parte del sicono, verdes a pardas en fresco, pardo grisáceas por la cara externa, amarillentas por la interna en seco; ostíolo (1-) $2 \times(1-) 2 \mathrm{~mm}$, aplanado a ligeramente prominente, 2 a 3 brácteas oclusivas visibles a simple vista, densamente pubescentes, el indumento amarillento; flores blancas en fresco.

Especie con distribución disyunta, ya que se le encuentra en México y Las Antillas, en tanto que en Sudamérica se ha colectado en Colombia, Ecuador y Perú (Berg y Villavicencio, 2004). En México se presenta en la vertiente del Pacífico, desde Sinaloa hasta Oaxaca y en Zacatecas. En el área de estudio se encuentra en los estados de México, Michoacán y Morelos (Figura 2B). Ficus membranacea habita preferentemente en el bosque de galería y en el bosque tropical caducifolio, y más raramente en la transición entre este último y el bosque de Quercus; su distribución altitudinal va de 700 a 1,950 m s.n.m.

Nombres comunes y usos: amate, amate blanco, amate prieto, saiba; usado como árbol de sombra.

Esta especie se caracteriza por sus pecíolos y láminas de similar longitud, con el haz y envés siempre glabros. Los atributos para distinguir F. membranacea de F. cotinifolia, especie con la que puede ser confundida, se sintetizan en el Cuadro 1. En el trabajo de Piedra-Malagón et al. (2006) esta especie fue descrita e ilustrada bajo el epíteto de Ficus sp.

Material examinado. Estado de México: Mpio. Otzoloapan: Tingambato, carretera Valle de Bravo, W. Boege 1773 (MEXU). Michoacán: Mpio. Tzitzio: a $1 \mathrm{~km}$ de Pie de la Mesa hacia Tzitzio, en la falla geológica, $N$. González 35 (IEB). Morelos: Mpio. Cuernavaca: Lomas de Tetela, $G$. Ibarra 5923 (IEB, MEXU, MO).

Ficus obtusifolia Kunth, Nov. Gen. Sp. (quarto ed.) 2: 49. 1817. (Figura 4G y 5G). F. bonplandiana (Liebm.) Miq.,
Ann. Mus. Bot. Lugduno-Batavum. 3: 298. 1867. F. involuta (Liebm.) Miq., Ann. Mus. Bot. Lugduno-Batavum. 3: 298. 1867.

Árbol hemiepífito o rupícola, de 4 a $20 \mathrm{~m}$ de alto; contrafuertes presentes; corteza lisa, gris a parda; raíces aéreas presentes; exudado blanco, abundante en la ramas jóvenes. Yema foliar 10-13 (-19) $\times(4-)$ 6-7 mm, indumentada, verde oscura en fresco; estípulas 10-13 (-19) × (4-) 6-15 mm, puberulentas a pilosas hacia el centro y glabrescentes hacia el margen por la cara externa, por la cara interna glabrescentes, en ocasiones ciliadas, verde oscuras a pardas en fresco. Entrenudos (3-) 5-9 (-15) × 6-8 mm, puberulentos a glabrescentes, pardos en fresco, cicatricosos. Pecíolo (10-) 12-17 (-23) × (1-) $2(-3) \mathrm{mm}$, glabro, verde pálido en fresco, profundamente acanalado; lámina foliar (8.5-) 12.4-15.4 $(-26.3) \times(3.6-) 5.1-6.6(-10.2) \mathrm{cm}$, obovada a oblanceolada, hojas comúnmente agrupadas hacia la yema foliar; base cuneada a redondeada, raramente obtusa o atenuada; ápice redondeado a obtuso, raramente emarginado; haz glabro, verde oscuro en fresco, liso, lustroso; envés glabro, verde pálido en fresco, liso, con (5-) 7-9 (-11) pares de venas secundarias. Sicono 12-16 × (11-) 14-15 (-17) mm, globoso a elipsoide, puberulento, verde pálido a verde oscuro con máculas amarillas en fresco; siconos comúnmente agrupados hacia la yema foliar, cuando jóvenes protegidos por un involucro caliptriforme, pardo oscuro, membranáceo, puberulento por las dos caras; pedúnculo (3-) 5-8 × (1-) 2-3 (-4) $\mathrm{mm}$, puberulento a glabrescente; brácteas basales 7-12 $\times$ 6-7 $\mathrm{mm}$, con el ápice redondeado, puberulentas por las dos caras, raramente cilioladas, persistentes, cubriendo desde un tercio hasta la mitad del sicono, en ocasiones sectadas, dando la impresión de ser 3 ó 4 brácteas; ostíolo 3-5 × 3-4 $\mathrm{mm}$, aplanado a prominente, con 3 brácteas oclusivas visibles a simple vista, puberulentas; flores pardo amarillentas o blancas en fresco.

Ficus obtusifolia habita desde México hasta Brasil. En la República Mexicana se distribuye por la vertiente del Pacífico desde Sinaloa hasta Chiapas y por la vertiente del Atlántico desde Tamaulipas hasta la Península de Yucatán, mientras que hacia el centro del país se le ha colectado en Hidalgo, Querétaro y San Luis Potosí. En la PBDB sólo se le registra en Guerrero, México y Michoacán (Figura 2B). En orden decreciente, se le encuentra en el bosque tropical subcaducifolio, bosque de Quercus, bosque mesófilo de montaña, bosque de galería y bosque tropical caducifolio; su distribución altitudinal va de 300 a 1,550 m s.n.m.

Nombres comunes y usos: amate, higuera.

Esta especie se reconocida por su lámina foliar obovada a oblanceolada, glabra, entrenudos gruesos, muy cicatricosos y brácteas basales cubriendo de un tercio a la mitad del higo. Ficus obtusifolia no puede ser confundida con ninguna otra especie en la región de estudio. Sin embargo, tomando en cuenta toda su área de distribución, pertenece al complejo taxonómico F. obtusifolia (Berg y Simonis, 1981), caracte- 
Ficus en la Provincia Biogeográfica del Balsas

rizado por hojas glabras, medianas a largas, siconos grandes cortamente pedunculados o sésiles y brácteas basales grandes.

Material examinado. Estado de México: Mpio. Amatepec: cercanía de Palmar Chico, E. Matuda 32191 (MEXU). Guerrero: Mpio. Teloloapan: Las Ceibitas km 96 carretera Iguala-Arcelia, casi $20 \mathrm{~km}$ al O de Teloloapan, H. H. Iltis 28704 (ENCB, F, MEXU). Michoacán: Mpio. La Huacana: alrededores del Ejido Agua Blanca, G. Ibarra 5966 (IEB, MEXU, MO).

Ficus pertusa L. f., Suppl. Pl. 442. 1782. (Figura 4H y 5H). F. padifolia Kunth, Nov. Gen. Sp. (quarto ed.). 2: 47.1817.

Árbol hemiepífito, a veces rupícola, de 5 a $35 \mathrm{~m}$ de alto; contrafuertes en ocasiones definidos; corteza lisa, gris clara, raramente pardo grisácea; raíces aéreas presentes; exudado blanco, abundante en las ramillas. Yema foliar (3-) 7-9 (17) $\times(1-) 2(-3) \mathrm{mm}$, glabra, verde clara en fresco; estípulas (3-) 7-9 (-17) $\times 2-4 \mathrm{~mm}$, glabras, verde claras en fresco. Entrenudos (5-) 10-23 (-40) $\times(1-)$ 2-4 mm, glabros a puberulentos, pardo grisáceos, pardos o amarillos en fresco y en seco, lisos a estriados. Pecíolo (13-) 20-24 (-39) × $1(-2)$ $\mathrm{mm}$, glabro a puberulento, verde pálido en fresco, acanalado; lámina foliar (5-) 7.4-9.3 (-12.4) × (1.8-) 3.4-3.9 (-5.3) $\mathrm{cm}$, elíptico-lanceolada a ovada; base cuneada a redondeada; ápice apiculado o agudo, a veces acuminado, raramente obtuso; haz glabro, verde oscuro en fresco, rugoso; envés glabro, verde pálido en fresco pero al secar las dos caras de la lámina adquieren colores similares, rugoso, con (5-) 7-8 (-11) pares de nervios secundarios. Sicono (5-) $10(-17) \times$ (6-) 10 (-16) mm, globoso a obloide, glabro a puberulento, verde cuando inmaduro a rojo o negro cuando maduro en fresco, sin máculas o éstas amarillas a rojas, en ocasiones ampolloso; pedúnculo (3-) 6-7 (-10) $\times 1 \mathrm{~mm}$, glabro a puberulento; brácteas basales diminutas de 1-2 × 2-3 mm, deltadas, ápice agudo o redondeado, glabras a puberulentas, a menudo persistentes, cubriendo menos de una cuarta parte del sicono; ostíolo (1-) 2 (-3) $\times(1-) 2$ (-3) mm, crateriforme, con dos a tres brácteas oclusivas visibles al microscopio; flores blancas en fresco.

Especie que se distribuye desde México, Centroamérica y Las Antillas hasta Paraguay y Brasil. En la República Mexicana tiene una amplia distribución, por la vertiente del Pacífico desde Sonora hasta Chiapas, por la vertiente del Atlántico desde Tamaulipas hasta Quintana Roo y en buena parte de los estados del centro, excepto en Aguascalientes, Coahuila, Nuevo León, Tlaxcala y Zacatecas. En la región de estudio falta colectarla en Jalisco y Oaxaca (Figura 2B). Ficus pertusa habita principalmente en los bosques tropicales tanto caducifolios como subcaducifolios, aunque también se presenta en el bosque de galería y el bosque de coníferas y raramente en los matorrales xerófilos; su distribución altitudinal va de 300 a 1,900 m s.n.m.

Nombres comunes y usos: amate, amesquite, camichín, camuchín, comuchín, higo de campo, jalamate, matapalo, palo bolero, samatito; el higo es comestible.

La especie se puede reconocer por su yema foliar glabra, relativamente delgada, lámina foliar elíptico lanceolada a ovada, glabra y siconos con el ostíolo crateriforme. De acuerdo con Berg (2007), F. pertusa constituye un complejo taxonómico que incluye seis formas en toda su área de distribución; en México se presenta la forma trachylosyce (siconos con el ostíolo tubular) y padifolia (ostíolo crateriforme), siendo esta última a la que pertenecen las plantas colectadas en la zona de estudio.

Material examinado. Estado de México: Mpio. Ixtapan de la Sal: $1 \mathrm{~km}$ al S de barranca Malinaltenango, A. García 6545 (MEXU). Guerrero: Mpio. Coyuca de Catalán: San Antonio, Distrito Montes de Oca, G. B. Hinton 11509 (ENCB, MEXU). Michoacán: Mpio. Apatzingán: $8 \mathrm{~km}$ west of Apatzingán, road to Buenavista, R. McVaugh 22883 (ENCB). Morelos: Mpio. Puente de Ixtla: Puente de Ixtla, río Tembembe, J. Vázquez 3056 (MEXU). Puebla: Mpio. Izúcar de Matamoros: Izúcar de Matamoros, E. Guízar 1290 (MEXU).

Ficus petiolaris Kunth, Nov. Gen. Sp. (quarto ed.) 2: 49. 1817. (Figura 5I y 6A). F. brandegei Standl., Contr. U.S. Natl. Herb. 20(1): 22. 1917. F. jaliscana S. Watson, Proc. Amer. Acad. Arts. 26: 150. 1891. F. palmeri S. Watson, Proc. Amer. Acad. Arts. 24: 77. 1889. F. petiolaris subsp. brandegei (Standl.) Felger \& Lowe, J. Arizona Acad. Sci. 6(1): 83. 1970. F. petiolaris subsp. jaliscana (S. Watson) Carvajal, Bol. Inst. Bot. Univ. Guadalajara. 8(1-2): 135. 2001. F. petiolaris subsp. palmeri (S. Watson) Felger \& Lowe, J. Arizona Acad. Sci. 6(1): 83. 1970.

Árbol rupícola, de 4 a $30 \mathrm{~m}$ de alto; contrafuertes ocasionalmente presentes, amarillos; corteza escamosa, amarilla, al exfoliarla se torna verde clara o verde amarillenta; raíces aéreas numerosas, anastomosantes, amarillas; exudado blanco, abundante en la ramillas y en los pecíolos. Yema foliar (10-) 22-26 (-55) × (4-) 5-7 (-10) $\mathrm{mm}$, puberulenta a pubescente, verde clara en fresco; estípulas (10-) 22-26 $(-55) \times 7-10 \mathrm{~mm}$, puberulentas a pubescentes, en ocasiones ciliadas, verde claras en fresco. Entrenudos (3-) 5-16 (-29) $\times$ (4-) $5(-8) \mathrm{mm}$, glabrados a indumentados, verdes a verde grisáceos en fresco, estriados. Pecíolo (44-) 76-94 (-170) × (1-) $2 \mathrm{~mm}$, casi tan largo como la lámina, glabro, a veces indumentado, verde a amarillo en fresco, a veces acanalado; lámina foliar (5.1-) 7.8-10.3 (-16.5) × (5.3-) 7.2-9.4 (-14.7) $\mathrm{cm}$, casi tan ancha como larga, cordiforme; base cordada a subcordada; ápice apiculado, rara vez redondeado a obtuso; haz glabro, a veces indumentado en la vena media, verde oscuro en fresco, liso, lustroso; envés con una agrupación de tricomas blancos en las axilas de los nervios basales, verde pálido en fresco, liso, con (5-) 7 (-9) pares de nervios secundarios. Sicono (7-) 10-12 (-17) $\times(9-)$ 12-14 (-19) mm, obloide, globoso o cortamente turbinado, puberulento, a ve- 
ces pubescente, raramente glabro, verde amarillento cuando inmaduro a rojo cuando maduro en fresco, máculas amarillo pálidas a rojas en fresco; pedúnculo (4-) 15-20 (-47) × (1) $2 \mathrm{~mm}$, puberulento, raramente glabrado; brácteas basales 2-4 × 3-5 mm, deltadas, a veces con el ápice redondeado, puberulentas por la cara externa, glabrescentes por la cara interna, persistentes, cubriendo hasta una cuarta parte del sicono; ostíolo (1-) 2-3 × (1-) 2 (-3) $\mathrm{mm}$, prominente, ocasionalmente cónico, brácteas oclusivas puberulentas; flores blancas en fresco.

Especie endémica a México, que se distribuye por la vertiente del Pacífico desde la Península de Baja California y Sonora hasta Oaxaca, y en el centro del país en los estados de Aguascalientes, Chihuahua, Durango, México, Morelos, Puebla y Zacatecas. Se ha colectado en los siete estados de la PBDB (Figura 3). Se le encuentra con mayor frecuencia en bosque tropical caducifolio, seguido de matorral xerófilo, bosque de galería, bosque tropical subcaducifolio y bosque de Pinus-Quercus; su distribución altitudinal va de 550 hasta 1,900 m s.n.m.

Nombres comunes y usos: amate, amate amarillo, saiba amarilla, siranda amarilla, tezcalamate; no se le conocen usos en el sitio de estudio.

Esta especie se reconoce fácilmente por su hábito exclusivamente rupícola, corteza amarilla y hojas cordiformes que en el envés tienen una agrupación de tricomas blancos en las axilas de los nervios basales. Una discusión detallada de su taxonomía puede consultarse en Piedra-Malagón et al. (en prensa).

Material examinado. Estado de México: Mpio. Tlatlaya: $2 \mathrm{~km}$ antes de Santa Ana Xicatecoyán, I. García 140 (INIF). Guerrero: Mpio. Cutzamala de Pinzón: $4 \mathrm{~km}$ al SO de Cañas Viejas, $20 \mathrm{~km}$ al NO de Nuevo Galeana, $F$. González 6100 (MEXU). Jalisco: Mpio. Valle de Juárez: Agua Caliente, C. L. Díaz 668 (IEB, XAL). Michoacán: Mpio. Apatzingán: Pocito de la Virgen, X. Madrigal 3161 (EBUM, ENCB, INIF, MEXU). Morelos: Mpio. Jantetelco: cerro de La Cantera, $R$. Cuevas 4631 (IEB, ZEA). Oaxaca: Mpio. Asunción Cuyotepeji: Cuyotepeji, P. Tenorio 17593 (F, MO). Puebla: Mpio. Molcaxac: Cañada de Mamacla, Tepexi de Rodríguez, $12 \mathrm{~km}$ al $\mathrm{O}$ de Molcaxac, R. Medina 416 (ENCB, MEXU, XAL).

Ficus pringlei S. Watson, Proc. Amer. Acad. Arts 26: 150. 1891. (Figura 5J y 6B).

Árbol rupícola, de 4 a 12 (-19) m de alto; contrafuertes presentes; corteza gris oscura a gris clara; raíces aéreas numerosas, anastomosantes, grises; exudado blanco, abundante en las ramillas. Yema foliar (4-) 6-9 (-10) $\times(1-)$ 2-3 (-4) $\mathrm{mm}$, indumentada, parda en fresco; estípulas (4-) 6-9 $(-10) \times(3-)$ 4-6 mm, pubescentes a puberulentas por la cara externa, indumentadas sólo en la base de la cara interna, en ocasiones cilioladas, pardas en fresco. Entrenudos (4-) 7-20 (-25) $\times(2-)$ 3-4 (-5) $\mathrm{mm}$, pilosos a pilósulos hacia la yema, pardos a grises en fresco, estriados. Pecíolo (5-) 7-12 $(-20) \times 1-2 \mathrm{~mm}$, piloso a ocasionalmente pilósulo, pardo a verde en fresco, ligeramente acanalado; lámina foliar (4.2) 5.4-6.2 (-7.8) × (2.5-) 3.7-4.2 (-6.1) cm, ovado deltada, en ocasiones cortamente ovada, margen ciliado, a veces ciliolado; base subcordada, rara vez cordada o redondeada a truncada; ápice agudo a obtuso, raramente redondeado; haz puberulento a pilósulo, verde oscuro en fresco, aterciopelado, opaco; envés piloso a rara vez pilósulo, casi del mismo tono que el haz en fresco, aterciopelado, opaco, con 5-7 (-9) pares de venas secundarias, las venas terciarias prominentes, reticuladas. Sicono 7-9 $\times(7-) 8(-10) \mathrm{mm}$, globoso a ligeramente obloide, pilósulo a puberulento, verde en fresco con máculas oscuras; siconos jóvenes protegidos por un involucro caliptriforme piloso por las dos caras; pedúnculo de (2-) 3-4 (-5) × 1-2 mm, piloso, o sin pedúnculo; brácteas basales 3-5 $\times 4-5 \mathrm{~mm}$, concrescentes, ápice redondeado a agudo, pilosas a ocasionalmente glabradas por las dos caras, ciliadas, persistentes, cubriendo hasta la mitad del higo, pardas en fresco y en seco; ostíolo $3 \times 3 \mathrm{~mm}$, cónico, brácteas oclusivas glabradas, cilioladas; flores pardo claras en seco.

Especie endémica de México, distribuida exclusivamente a lo largo de la vertiente del Pacífico, desde Nayarit hasta Guerrero. En la región de estudio sólo se ha colectado en Guerrero y Michoacán (Figura 2A). Ficus pringlei es una especie típica del bosque tropical caducifolio y se le encuentra con una menor frecuencia en bosque de galería, bosque tropical subcaducifolio y bosque de Pinus, entre altitudes de 250 y 1,300 m s.n.m.

Esta especie se caracteriza por la venación terciaria prominente y reticulada, el ostíolo cónico y siconos sésiles o pedunculados. Ha sido confundida con Ficus cotinifolia (Cuadro 1) y con F. kellermanii Standl. Este último binomio es un sinónimo de $F$. crassinervia Desf. ex Willd., un taxón que no se ha colectado en la PBDB.

Material examinado. Guerrero: Mpio. Cutzamala de Pinzón: $8 \mathrm{~km}$ al NO de Cañas Viejas, F. González 6119, 6135 (MEXU). Michoacán: Mpio. La Huacana: Jorullo Volcano, W. A. Eggler 137 (MO).

Ficus velutina Humb. \& Bonpl. ex Willd., Sp. Pl. 4: 1141. 1806. (Figura 5K y 6C). F. glycicarpa (Miq.) Miq., Ann. Mus. Bot. Lugduno-Batavum. 3: 297. 1867. F. microchlamys Standl., Contr. U.S. Natl. Herb. 20(1): 23. 1917.

Árbol rupícola o excepcionalmente hemiepífito, de 6 a $40 \mathrm{~m}$ de alto; contrafuertes definidos; corteza lisa, parda a gris; raíces aéreas anastomosantes, pardas a grises; exudado blanco que se torna amarillento al oxidarse, abundante en las ramillas. Yema foliar (6-) 9-12 (-21) × (2-) 3-4 (-6) mm, indumentada, ferrugínea a blanco amarillenta; estípulas (6-) 9-12 (-21) × 6-8 mm, seríceas con el indumento ferrugíneo a canoso amarillento por la cara externa, glabras por la cara interna, ciliadas, pardo ferrugíneas a blanco amarillentas en fresco y en seco. Entrenudos (4-) 10-31 (-68) × (3-) 4-5 (-7) 

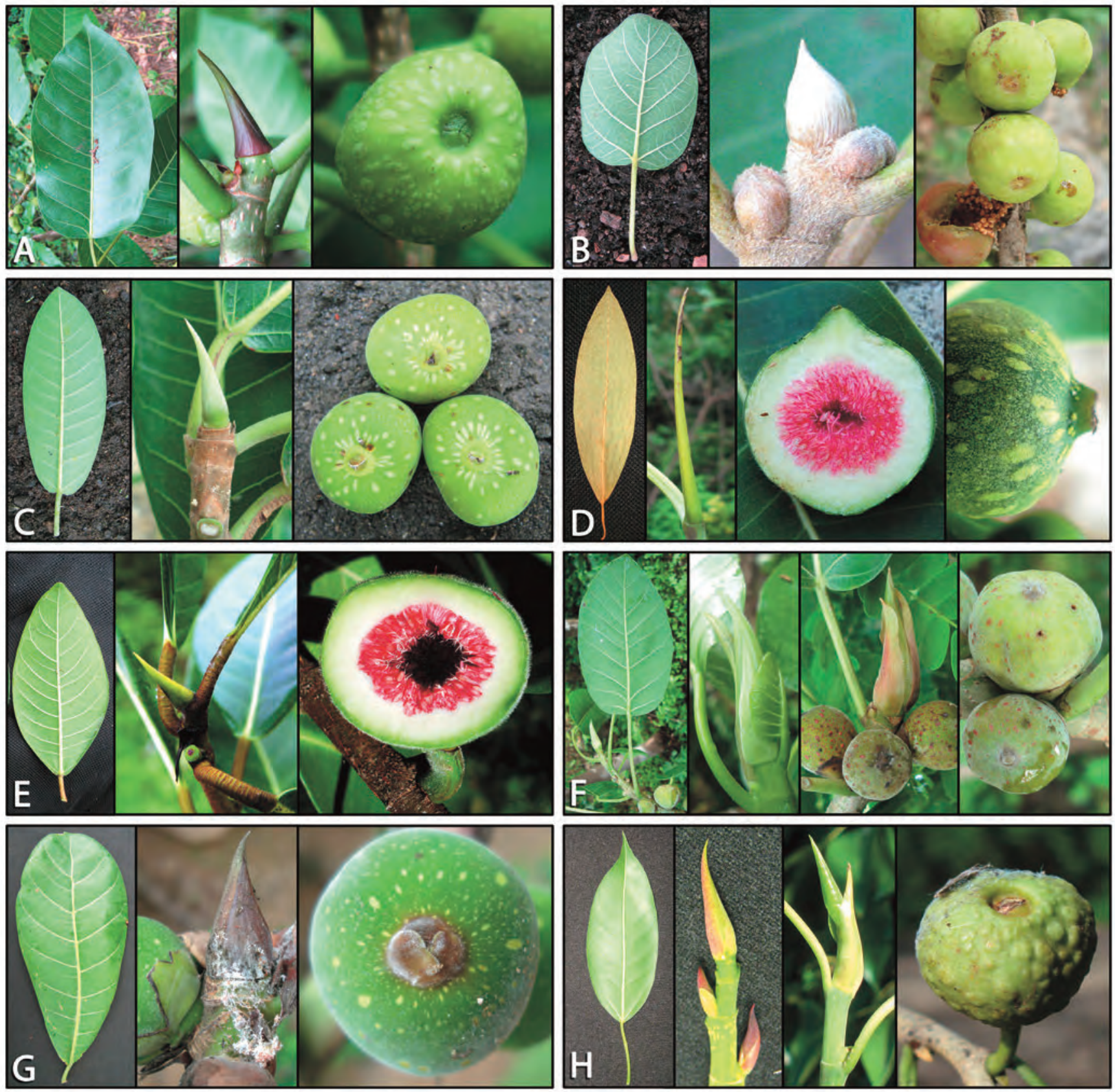

Figura 4. Hoja, yema foliar y sicono de las especies: A) F. citrifolia, B) F. cotinifolia, C) F. crocata, D) F. insipida, E) F. maxima, F) F. membranacea, G) F. obtusifolia y H) F. pertusa.

$\mathrm{mm}$, tomentosos a pilosos hacia la yema, glabrescentes hacia la ramilla, con el indumento ferrugíneo, pardo grisáceos a ferrugíneos en fresco, aterciopelados. Pecíolo (10-) 16-23 $(-40) \times 2-3 \mathrm{~mm}$, tomentoso a pubescente, ocasionalmente puberulento, con el indumento ferrugíneo a canoso, pardo a verde en fresco, ligeramente acanalado; lámina foliar (6.8-) 10.1-13.6 (-19.1) × (3.4-) 5.2-6.8 (-9.9) cm, elíptica a elíptica ovada, a veces elíptica obovada o lanceolada, eventualmente con el margen revoluto; base ligeramente subcor- dada, raramente obtusa o redondeada; ápice agudo a obtuso, ocasionalmente redondeado; haz pilósulo a glabrado, a veces piloso únicamente en la vena media o en las venas secundarias, verde oscuro en fresco, opaco, ligeramente áspero a liso; envés tomentoso a puberulento, ocasionalmente piloso, con el indumento ferrugíneo a canoso, verde pálido en fresco, opaco, comúnmente aterciopelado, con (6-) 11-12 (-14) pares de venas secundarias. Sicono (10-) 13-14 (-20) $\times(10-)$ 13-15 (-18) mm, globoso a cortamente turbinado, 

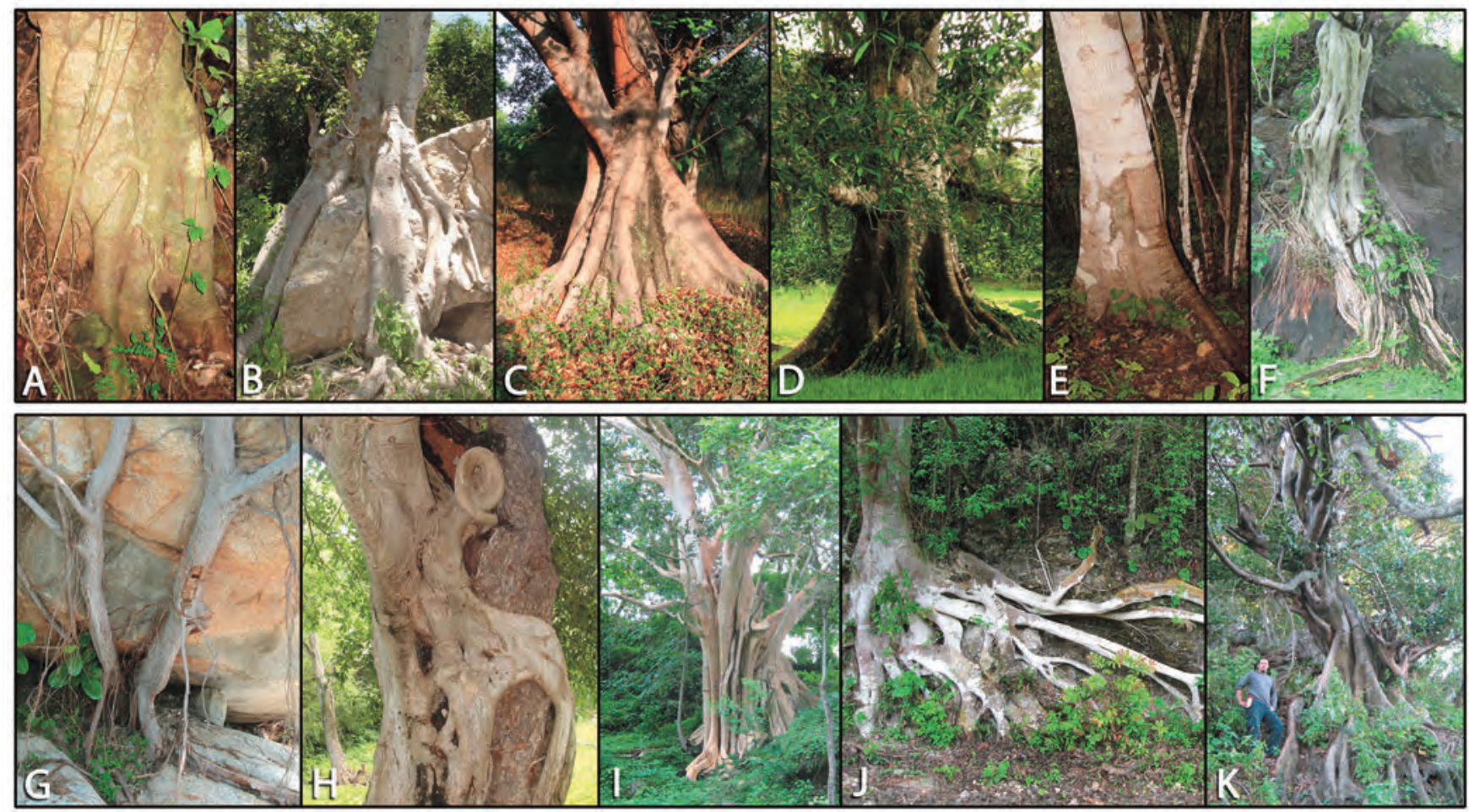

Figura 5. Hábito de crecimiento de las especies: A) F. citrifolia, B) F. cotinifolia, C) F. crocata, D) F. insipida, E) F. maxima, F) F. membranacea, G) F. obtusifolia, H) F. pertusa, I) F. petiolaris, J) F. pringlei y K) F. velutina.
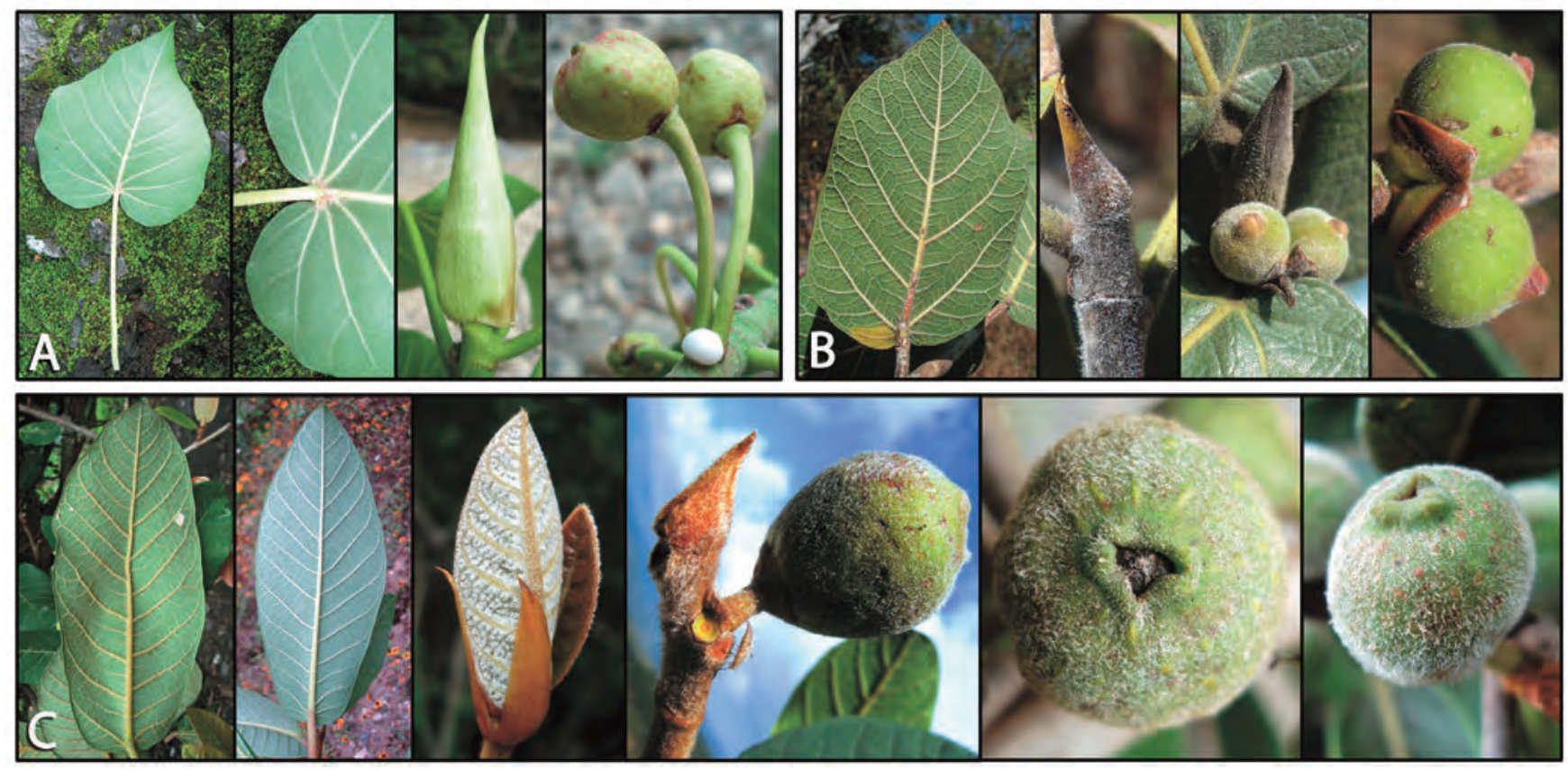

Figura 6. Hoja, yema foliar y sicono de las especies: A) F. petiolaris, B) F. pringlei y C) F. velutina.

tomentoso, pubescente o puberulento, con el indumento canoso, verde con máculas amarillas a rojizas en fresco; el par de siconos jóvenes protegidos por un involucro caliptriforme seríceo a puberulento por la cara externa, glabro por la interna; pedúnculo (3-) 5-6 (-9) × 1-2 mm, tomentoso a pubescente, a veces puberulento, con el indumento ferrugíneo; brácteas basales $2-4 \times 2-4 \mathrm{~mm}$, ocasionalmente hendidas, tomentosas, seríceas o puberulentas por la cara externa, gla- 
bras por la interna, en ocasiones ciliadas, persistentes, cubriendo menos de la cuarta parte del higo; ostíolo (2-) 3 (-4) $\times(1-) 3(-4) \mathrm{mm}$, prominente, rara vez aplanado, rodeado por un anillo circular a triangular, tres brácteas oclusivas visibles al microscopio, glabras, ciliadas; flores blancas a rosa pálido en fresco.

Árboles que se distribuyen desde México hasta Colombia y Venezuela. En México se le ha registrado en la vertiente pacífica de Sinaloa a Chiapas, en la vertiente atlántica en Veracruz y Campeche, y en el centro del país en Durango, México, Morelos, Puebla y Zacatecas. Esta especie se ha colectado en los siete estados de la PBDB (Figura 3) y es un elemento característico de la transición entre el bosque de Quercus y el bosque tropical caducifolio, además se puede encontrar en el bosque tropical subcaducifolio, bosque mesófilo de montaña y excepcionalmente en bosque de Pinus; su distribución altitudinal va de 900 a 2,200 m s.n.m, pero se encuentra con mayor frecuencia entre 1,500 y 2,000 m.

Nombres comunes y usos: amate, amate silvestre, higuera, saiba, siranda.

Ficus velutina se caracteriza por sus estípulas seríceas y ciliadas, con el indumento ferrugíneo a blanco amarillento, un tipo de pubescencia que también se observa en los entrenudos, sobre todo los que se encuentran en las partes jóvenes de la ramilla, sicono con el indumento blanco y ostíolo rodeado por un anillo circular a triangular. Se puede confundir con Ficus crocata (Cuadro 2), ya que las dos especies pertenecen al mismo complejo taxonómico (Berg y Simonis, 1981).

Material examinado. Estado de México: Mpio. Malinalco: Chalma, carretera Chalma-Malinalco, orilla de un cuerpo de agua, I. Martínez 969 (IEB). Guerrero: Mpio. Eduardo Neri: La Laguna, $18 \mathrm{~km}$ al SO de Xochipala, J. C. Soto 5172 (MEXU). Jalisco: Mpio. Tecalitlán: $10 \mathrm{~km}$ al S de Tecalitlán, J. Rzedowski 15311 (ENCB, INIF, MEXU). Michoacán: Mpio. Cotija: $1 \mathrm{~km}$ al SO de Gallineros, I. García 5008 (IEB), 3297 (CIMI). Morelos: Zona Arqueológica Tepoztlán, cerro Tepozteco, $30 \mathrm{~km}$ al SE de Cuernavaca, J. S. Miller 3000 (MEXU, MO). Oaxaca: Mpio. Santos Reyes Tepejillo: La Cruz, $3 \mathrm{~km}$ al N de Santos Reyes Tepejillo, río Boquerón, J. I. Calzada 9340 (MEXU). Puebla: Mpio. Izúcar de Matamoros: Izúcar de Matamoros, W. Boege 1442 (MEXU).

\section{Agradecimientos}

Agradecemos a los curadores y personal de apoyo de los herbarios consultados por las facilidades para la consulta del material examinado. A Jesús Fuentes Junco por su apoyo para la elaboración de las Figuras 1-3 y a Alberto Valencia García por su apoyo para la elaboración de las Figuras 4-6. Eva María Piedra Malagón y Nuria Avendaño Astorga apoyaron diversos aspectos del trabajo de campo. Esta última actividad fue respaldada por el Programa de Apo- yo a Proyectos de Investigación e Innovación Tecnológica (PAPIIT), de la Dirección General de Asuntos del Personal Académico (DGAPA), Universidad Nacional Autónoma de México, en el proyecto "Diversidad y biogeografía del género Ficus (Moraceae) en México”, clave IN229107-3. Los comentarios de dos árbitros anónimos y de la Dra. Victoria Sosa fueron de gran ayuda para mejorar el manuscrito.

\section{Literatura Citada}

Arias S. y Terrazas T. 2008. $\times$ Pachebergia (Cactaceae), a nothogenus from western Mexico. Revista Mexicana de Biodiversidad 79:23-28.

Berg C.C. 1989. Classification and distribution of Ficus. Experientia 45:605-611.

Berg C.C. 2001. Moreae, Artocarpeae, and Dorstenia (Moraceae), with introductions to the family and Ficus and with additions and corrections to Flora Neotropica Monograph 7. Flora Neotropica Monograph 83:1-347.

Berg C.C. 2006. The subdivision of Ficus subgenus Pharmacosycea section Pharmacosycea (Moraceae). Blumea 51:147-151.

Berg C.C. 2007. Proposals for treating four species complexes in Ficus subgenus Urostigma section Americanae (Moraceae). Blumea 52:295-312.

Berg C.C. y Simonis J.E. 1981. The Ficus flora of Venezuela: five species complexes discussed and two new species described. Ernstia 6:1-11.

Berg C.C. y Villavicencio X. 2004. Taxonomic studies on Ficus (Moraceae) in the West Indies, extra-Amazonian Brazil, and Bolivia. Ilicifolia 5:3-129.

Carvajal S. 2007. Moraceae. Flora del Bajío y de Regiones Adyacentes 147:1-59.

Carvajal S. y Peña-Pinela C. 1997. Ficus jacquelineae (Moraceae, subgen. Urostigma) a new name for a mexican fig. Boletín del Instituto de Botánica Universidad de Guadalajara 4:1-3.

Carvajal S. y Shabes L.K. 1998. Two new subsections of the american species of the genus Ficus L. (Moraceae, subgenus Pharmacosycea Miq., section Pharmacosycea). Boletín del Instituto de Botánica Universidad de Guadalajara 6:213-217.

CONABIO (Comisión Nacional para el Conocimiento y Uso de la Biodiversidad). 1997. Provincias Biogeográficas de México. Escala 1:4000000. México.

Cué-Bär E.M., Villaseñor J.L., Arredondo-Amezcua L., CornejoTenorio G. e Ibarra-Manríquez G. 2006. La flora arbórea de Michoacán, México. Boletín de la Sociedad Botánica de México 78:47-81.

Datwyler S.L. y Weiblen G.D. 2004. On the origin of the fig: phylogenetic relationships of Moraceae from ndhF sequences. American Journal of Botany 91:767-777.

Diego-Pérez N. y Calderón G. 2004. Un nuevo género de Cruciferae (Brassicaceae) del estado de Guerrero, México. Acta Botánica Mexicana 68:73-79.

Durán-Ramírez C.A., Fonseca-Juárez R.M. e Ibarra-Manríquez G. 2010. Estudio florístico de Ficus (Moraceae) en el estado de Guerrero, México. Revista Mexicana de Biodiversidad 81: 239-262.

Escalante-Pliego P., Navarro-Sigüenza A.G. y Peterson A.T. 1998. Un análisis geográfico, ecológico e histórico de la diversidad de aves terrestres de México. En: Ramamoorthy T.P., Bye R., 
Lot A. y Fa J. Eds. Diversidad biológica de México: orígenes y distribución, pp.279-304. Universidad Nacional Autónoma de México, Distrito Federal.

Espinosa-Organista D., Morrone J.J., Aguilar-Zuñiga C. y Llorente-Bousquets J. 2000. Regionalización biogeográfica de México: Provincias bióticas. En: Llorente-Bousquets J., González E. y Papavero N. Eds. Biodiversidad, taxonomía y biogeografía de artrópodos de México: Hacia una síntesis de su conocimiento, Vol. II, pp.61-94, Universidad Nacional Autónoma de México, Distrito Federal.

Fernández-Nava R., Rodríguez-Jiménez C., Arreguín-Sánchez M. y Rodríguez-Jiménez A. 1998. Listado florístico de la cuenca del río Balsas, México. Polibotánica 9:1-151.

Ferrusquía-Villafranca I. 1992. Regionalización Biogeográfica IV.8.10. En: Atlas Nacional de México, Tomo II. Escala 1:4,000,000. Instituto de Geografía, Universidad Nacional Autónoma de México.

García E. 2004. Modificaciones al sistema de clasificación climática de Köppen. Instituto de Geografía, Universidad Nacional Autónoma de México. México, D.F.

Guízar-Nolazco E. y Sánchez-Velez A. 1991. Guía para el reconocimiento de los principales árboles del Alto Balsas. Universidad Autónoma Chapingo. Texcoco, México.

Harrison R.D. 2005. Figs and the diversity of tropical rainforests. Bioscience 55:1053-1064.

Ibarra-Manríquez G. 1991. Ficus (Moraceae): un género interesante para estudios en ecología y sistemática tropical. Ciencia 42:283-293.

Ibarra-Manríquez G. y Wendt T.L. 1992. El género Ficus, subgénero Pharmacosycea (Moraceae) en Veracruz, México. Boletín de la Sociedad Botánica de México 52:3-29.

INEGI (Instituto Nacional de Estadística, Geografía e Informática). 1990. División Política Estatal. I.1.2. Atlas Nacional de México. Vol. I. Escala 1:4000000. Instituto de Geografía, Universidad Nacional Autónoma de México. México.

Janzen D.H. 1979. How to be a fig. Annual Review of Ecology and Systematics 10:13-51.

Lambert F.R. y Marshall A.G. 1991. Keystone characteristics of bird-dispersed Ficus in a Malaysian lowland rain forest. Journal of Ecology 79:793-809.

Moreno N.P. 1984. Glosario Botánico Ilustrado. Instituto Nacional de Investigaciones sobre Recursos Bióticos. Xalapa, Veracruz.

Morrone J.J. 2005. Hacía una síntesis biogeográfica de México. Revista Mexicana de Biodiversidad 76:207-252.

Morrone J.J., Espinosa-Organista D. y Llorente-Bousquets J. 2002. Mexican biogeographic provinces: preliminary scheme, general characterizations, and synonymies. Acta Zoológica Mexicana 85:83-108.

Piedra-Malagón E.M., Ramírez-Rodríguez R. e Ibarra-Manríquez
G. 2006. El género Ficus (Moraceae) en el estado de Morelos, México. Acta Botánica Mexicana 75:45-75.

Piedra-Malagón E.M., Sosa V. e Ibarra-Manríquez G. (en prensa). Clinal variation and species boundaries in the Ficus petiolaris complex. Systematic Botany.

Quintana-Cardoza R. y Carvajal S. 2001. Las especies jaliscienses del género Ficus L. (Moraceae). Boletín del Instituto de Botánica Universidad de Guadalajara 8:1-64.

Ramírez-Pulido J. y Castro-Campillo A. 1992. Regionalización Maustofaunística IV.8. 8. En: Atlas Nacional de México, Tomo II. Escala 1:4,000,000. Instituto de Geografía, Universidad Nacional Autónoma de México.

Rodríguez-Jiménez C., Fernández-Nava R., Arreguín-Sánchez M. y Rodríguez-Jiménez A. 2005. Plantas vasculares endémicas de la cuenca del río Balsas, México. Polibotánica 20:73-99.

Rzedowski J. 1978. Vegetación de México. Limusa. México, D. F.

Rzedowski J., Medina-Lemos R. y Calderón G. 2004. Las especies de Bursera (Burseraceae) en la cuenca superior del río Papaloapan (México). Acta Botánica Mexicana 66:23-151.

Schilling E.E. 2008. Paneroa, a new genus of Eupatorieae (Asteraceae) from Mexico. Novon 18:520-523.

Serrato A., Ibarra-Manríquez G. y Oyama K. 2004. Biogeography and conservation of the genus Ficus (Moraceae) in México. Journal of Biogeography 31:475-485.

Shanahan M., So S., Compton S.G. y Corlett R. 2001. Fig-eating by vertebrate frugivores: a global review. Biological Reviews 76:529-572.

Smith C.M. y Bronstein J.L. 1996. Site variation in reproductive synchrony in three neotropical figs. Journal of Biogeography 23:477-486.

Sousa M. 2005. Heteroflorum: un nuevo género del grupo Peltophorum (Leguminosae: Caesalpinioideae: Caesalpinieae), endémico para México. Novon 15:213-218.

Standley P.C. 1917. The Mexican and Central American species of Ficus. Contributions from the United States National Herbarium 20:1-35.

Standley P.C. 1922. Trees and shrubs of Mexico. Contributions from the United States National Herbarium 23:171-515.

Stearn W.T. 1983. Botanical Latin. David \& Charles. Inglaterra.

Terborgh J. 1992. Diversity and the tropical rain forest. Scientific American Library. Nueva York.

Toledo A. 2003. Ríos, costas, mares. Hacia un análisis integrado de las regiones hidrológicas de México. Instituto Nacional de Ecología. México, D.F.

Trejo-Vázquez I. 1999. El clima de la selva baja caducifolia en México. Investigaciones Geográficas 39:40-52.

Vázquez-Ávila M.D. 1981. El género Ficus (Moraceae) en la República Argentina. Darwiniana 23:605-636.

Recibido: 29 de enero del 2010

Aceptado: 27 de octubre del 2010 
Apéndice. Colectores, número de colecta y herbarios donde se encuentran depositados los especímenes revisados en el presente estudio, arreglados por especie y orden alfabético. Para cada colector se indica su apellido paterno y las iniciales de su(s) nombres(s).

\section{Ficus cotinifolia}

Aguilar, V., 71 (FCME).

Alcaraz, P., 5 (ENCB, INIF, MEXU).

Almazán, A., 259 (MEXU).

Amith, J., 444 (MEXU).

Boege, W., 2232, 2302 (MEXU).

Bonilla, J., 1421 (FCME, MO).

Bustamante, R. C., 342, 504 (HUMO).

Calónico, J., 1576, 2121, 14372 (FCME, HUAP, HUMO); 15498b (MEXU).

Calzada, J. I., 20323 (MEXU); 20678 (CH, CICY, MEXU, $\mathrm{MO}$ ).

Campos, G., 586 (FCME).

Casarrubias, J., 122 (MEXU).

Castañeda, A., 1, 297 (MEXU).

Castro, R., 151 (HUMO).

Catalán, C., 446 (IEB), 597 (IEB, MEXU); 756 (MEXU).

Cerros, R., 345b, 542 (HUMO).

Chávez, E., 104 (FCME).

Contreras, J. L., 399 (FCME, MEXU); 7698 (HUAP, XAL).

Cruz, R., 707, 752 (FCME, MEXU); 6516 (FCME).

Díaz, J. M., 240 (ENCB).

Durán, C. A., 61, 66, 67, 68, 93, 97 (MEXU).

Eggler, W. A., 205 (MO).

Espinosa, J., 838 (ENCB, INIF).

Estrada, L. E., 1117 (MEXU).

Flores, G., 742 (MEXU).

Freeland, J., 44 (MEXU).

García, A., 7473 (MEXU).

García, I., 299, 6778 (CIMI).

González, F., 4105, 5076 (MEXU).

González, N., 21, 32, 39, 41 (IEB, MEXU, MO).

González, R. E., 271 (IEB, FCME, MEXU).

Gual, M., 378, 382 (FCME).

Guerrero, F., 108 (FCME).

Guízar, E., 203 (ENCB, INIF, MEXU, XAL); 1058 (ENCB, MEXU, XAL); 1360 (ENCB, MEXU); 1833 (IEB, MEXU); 3552 (MEXU); 4026 (CH, HUAP, HUMO, IEB, INIF, MEXU, XAL); 4344 (HUMO, MEXU).

Ibarra, G., 5922, 5963 (IEB, MEXU, MO).

Juárez, J. C., 171 (HUMO).

Kruse, H., 2451 (MEXU).

López, A. R., 33 (FCME).

Lorea, F., s. n. (FCME).

Ludlow, B., 106, 140, 153, 175, 217, 264 (MEXU).

Luna, M., 66, 123 (FCME).

Maldonado, B., 1245 (HUMO).

Martínez, E., 660 (MEXU); 1413 (ENCB, MEXU, MO).

Matuda, E., 26994 (MEXU).
Medina, R., 66, 607 (MEXU).

Mendoza, M., 34 (EBUM).

Miranda, A. G., 904, 1283, 1378, 1484, 2061, 3953, 9293, 9327 (MEXU).

Monzon, A. G., s. n. (FCME).

Moore, H. E., 5658 (MEXU).

Morales, F., 116 (MEXU).

Moreno, E., 1071 (FCME).

Núñez, M., 4 (MEXU).

Palacios, R., 1450, s. n. (ENCB).

Peralta, S., 55, 147 (FCME).

Piedra, E. M., 117, 126, 127 (HUMO, XAL); 151 (HUMO, IEB, MEXU, XAL).

Quezada, R. M., 773 (MEXU).

Ramírez, A., 660, 953 (HUMO).

Ramírez, W., s. n. (F).

Razo, R., 43 (MEXU).

Rendón, H., 480 (EBUM, IEB).

Reyes, J., 548 (MEXU).

Rodríguez, M., 261 (HUAP).

Ruiz, R., 2219 (MEXU).

Rzedowski, J., 18692 (ENCB, MEXU).

Soto, J. C., 138, 4346, 4641 (ENCB, MEXU); 688, 3006

(MEXU, XAL); 3862, 3962, 9203, 9286 (MEXU); 4841

(ENCB, MEXU, MO); 8737 (IEB, MEXU).

Soto, L., 215 (FCME).

Steinmann, V. W., 3385, 3417 (IEB, MEXU).

Terán, F. 488 (FCME, MEXU); 514 (FCME).

Torres, B., 92, 420 (MEXU); 411 (FCME).

Vargas, A., 452 (FCME, MEXU).

Vázquez, J., 2549, 3081 (MEXU).

Vela, L., s. n. (ENCB, INIF).

Villa, A., 802 (MEXU).

Viveros, J. L., 390 (MEXU, MO).

\section{Ficus crocata}

Boege, W., 2154 (MEXU).

Bonfil, A., 176 (ENCB).

Bonilla, R., s. n. (ENCB).

Calónico, J., 517 (FCME); 10072, 14907 (FCME, HUMO).

Cházaro, M., 7083 (IEB).

Cruz, R., 847 (FCME); 2217 (FCME, HUMO).

Durán, C. A., 96 (MEXU).

Eggler, W. A., 147 (MO).

Espinosa, J., 829 (ENCB).

Gallardo, A., s. n. (FCME).

García, I., 282, 305, 6358, 6473 (CIMI).

González, F., 4003 (MEXU, MO); 5746 (ENCB, MEXU, XAL).

González, N., 2, 26, 45 (MEXU); 30, 37 (IEB, MEXU, MO); 
Apéndice. Continuación

38 (IEB, MEXU); 40 (F, IEB, MEXU, MO).

Guerrero, B., 1436 (XAL).

Guízar, E., 219 (ENCB, INIF, MEXU, XAL); 285 (INIF, MEXU, XAL); 1533 (IEB).

Gutiérrez, P. M., 980 (MEXU); 1510 (HUMO).

Ibarra, G. 5961 (IEB, MEXU); 5964 (IEB, MEXU, MO).

Iltis, H. H., 28702 (ENCB, F, MEXU).

Juárez, J. C., 190 (HUMO).

Kimnach, M., 2303 (MEXU).

Madrigal, X., 4838 (EBUM).

Matuda, E., 37377 (MEXU).

Mendizábal, L., 61 (FCME).

Miranda, F. A., 224, 1198, 2041,2587 (MEXU).

Moore, H. E., 5648 (MEXU).

Moreno, E., 897, 973 (FCME); 1029 (FCME, HUAP).

Ortiz, S. A., 102 (MEXU).

Palacios, R., s. n. (ENCB, INIF).

Piedra, E. M., 140 (XAL); 232 (MEXU, XAL).

Ramírez, D., s. n. (MEXU).

Ramírez, R., 35 (ENCB).

Redonda, R., 191 (FCME).

Rodríguez, D., 113 (HUMO).

Rzedowski, J., 31874 (ENCB).

Sánchez, M. J., 93 (MEXU).

Soto, J. C., 3888, 4644, 7607, 8232 (IEB, MEXU); 4313, 4851, 6222, 7603, 7699, 7773, 8018, 6696 (MEXU); 4986 (HUMO, IEB, MEXU).

Steinmann, V. W., 5404 (IEB).

Torres, B., 419 (MEXU).

Urbina, M., s. n. (MEXU, XAL).

Valencia, S., 1301 (MEXU).

Vázquez, J., 2433 (MEXU).

Vázquez, V., 622, 668 (XAL).

\section{Ficus insipida}

Amith, J., 402 (MEXU).

Boege, W., 2155 (MEXU).

Bonfil, A., 37 (ENCB).

Bravo, H., 142 (MEXU).

Calónico, J., 8245b (MEXU); 15165 (FCME, MEXU); 15870 (FCME).

Calzada, J. I., 16095 (FCME, MEXU).

Castañeda, A., 473 (MEXU).

Castillo, P., 6927 (MEXU).

Castro, R., 75 (HUMO).

Catalán, C., 213 (IEB, MEXU).

Clark, O. M., 7102 (MO).

Contreras, J. L., 1035 (FCME).

Cruz, R., 3842 (MEXU); 6083 (FCME).

Delgado, O., 1194 (FCME).

Durán, C. A., 65 (MEXU).
Flores, H. E., 43, 80 (HUMO).

Freeland, J., 35 (MEXU).

García, I., 161, 6540 (CIMI).

García, O., 80 (FCME).

González, B., 1807 (MEXU).

González, F., 5468 (MEXU, XAL).

González, L., 3633 (ENCB).

González, N., 24, 36 (IEB, MEXU, MO).

Guízar, E., 220 (ENCB, MEXU, XAL); 889 (MEXU); 1436

(ENCB, MEXU); 1965 (IEB, MEXU); 2312 (IEB, MEXU, XAL).

Hinton, G. B., 7309 (HUMO); 8888 (HUMO, MO).

Ibarra, G., 5924 (IEB, MEXU).

Iltis, H. H., 28703 (ENCB, F, MEXU).

Juárez, J. C., 297 (HUMO); 2034, 2505 (MEXU, MO); 8019

(MEXU, XAL); 8572 (IEB, MEXU).

Leavenworth, W. M. C., 1338, 1430 (F, MO).

Madrigal, X., 4836 (EBUM).

Martínez, A., 62 (ENCB, IEB).

Martínez, E. 1283 (ENCB, MEXU).

Martínez, M., s. n. (F).

Matuda, E., 30698 (MEXU, MO).

Meza, M., s. n. (FCME).

Miller, J. S., 2899 (MO).

Miranda, F. A., 1210, 1337 (MEXU).

Moreno, E., 1041 (FCME).

Palacios, R., s. n. (ENCB).

Piedra, E. M., 110, 122, 142, 158 (HUMO, XAL).

Ramírez, G. D., 46a (HUMO).

Rangel, S., 788 (EBUM, IEB).

Rivera, I., s. n. (MEXU).

Rodríguez, T., 132 (HUMO).

Rzedowski; J., 16652 (ENCB); 18694 (ENCB, XAL); 31875

(ENCB, MEXU).

Salazar, L., 28 (HUMO).

Soto, J. C., 2325 (ENCB, MEXU); 8643 (MEXU); 8747 (IEB, MEXU).

Steinmann, V. W., 3120 (IEB).

Tenorio, P., 14205 (MEXU).

Terán, F., 30 (MO).

Torke, K., 342 (ENCB, MO).

Torres, B., 223, 348 (FCME).

Valdez, A., 266 (HUMO).

Valencia, J., 6 (INIF)..

Valencia, S., 1031 (FCME); 1214 (FCME, MEXU).

Vargas, E., 79 (MEXU).

Vázquez, J., 2432 (MEXU).

Vázquez, V., 604, 669 (XAL).

Woronow, G., 2549 (F).

Ficus maxima

Alcántara, O., 5813 (FCME).

Cruz, R., 6082 (FCME). 
Apéndice. Continuación

Flores, A., 915b (XAL).

García, A., 6625 (MEXU).

García, I., 7045 (CIMI).

González, N., 28 (IEB, MEXU, MO).

Granados, C., s. n. (FCME).

\section{Ficus membranacea}

Flores, H. E., 30, 69 (HUMO).

García, I., 307, 6573, 7078 (CIMI).

González, N., 25, 100 (IEB, MEXU); 42 (IEB, MEXU, MO).

Ibarra, G., 5925, 5926 (IEB, MEXU, MO).

Madrigal, X., 4792 (EBUM).

Matuda, E., 37410 (F).

McVaugh, R., 22652 (ENCB).

Piedra, E. M., 154, 159 (HUMO, XAL).

Ramírez, R., 1803 (HUMO).

Ramírez, Y., 616 (IEB).

\section{Ficus obtusifolia}

Alcántara, O., 5808 (FCME).

Calónico, J., 14853 (FCME, HUMO, MEXU).

Cruz, R., 6151 (FCME).

Espinosa, J., 840 (ENCB, INIF).

Matuda, E., 27040, 27476 (MEXU); 37446 (F, INIF, MEXU).

Peralta, S., 587 (MEXU).

Soto, J. C., 4944 (IEB, MEXU).

Zepeda, C., 510 (MEXU).

\section{Ficus pertusa}

Cházaro, M., 5597 (ENCB, IEB, XAL).

Durán, C. A., 95 (MEXU).

Espinosa, J., 42 (ENCB, INIF).

Freeland, J., 59 (MEXU).

Fuchs, F. M., 1735 (MEXU).

García, I., 7171 (CIMI).

González, L., 3625 (ENCB).

González, N., 27 (IEB, MEXU, MO).

Gutiérrez, P. M., 798 (MEXU).

Huerta, M., 45 (MEXU).

Ibarra, G., 5956 (IEB, MEXU, MO).

Leavenworth, W. M. C., 1343, 1439, 1559 (F, MO).

Ludlow, B., 138 (MEXU).

Madrigal, X., 2056, 2067 (INIF).

Martínez, A., 68 (ENCB, IEB, MEXU).

McVaugh, R., 22655 (ENCB).

Miranda, F. A., 1357, 1368 (MEXU).

Moctezuma, F. G., s. n. (MEXU).

Ortiz, M., 414 (ENCB, FCME, MEXU).

Palacios, R., s. n. (ENCB).

Paray, L., 699 (ENCB).

Piedra, E. M., 124 (HUMO, XAL); 230 (XAL, MEXU).
Ramírez, G. D., 46b (HUMO).

Rose, J. N., 4350 (F).

Rzedowski, J., 21830 (ENCB).

Schiede, G., 29 (MO).

Soto, J. C., 8032 (FCME, MEXU, XAL); 8073 (MEXU).

Takaki, F., s. n. (ENCB).

Tejero, D., 2850 (IEB).

Urbina, M., s. n. (MEXU, XAL).

Vázquez, J., 1841 (MEXU).

Villa, A., 677 (MEXU).

\section{Ficus petiolaris}

Betancourt, C., 40 (HUMO).

Boege, W., 2303 (MEXU).

Calónico, J., 8582 (FCME, HUMO).

Calzada, J. I., 18468 (MEXU); 20880 (MEXU, XAL).

Catalán, C., 214 (IEB).

de Jesús, J. M., 756 (HUMO).

Durán, C. A., 64, 94 (MEXU).

Dziekanowski, C., 3107 (INIF, MO).

Estrada, L. E., 1165 (MEXU).

Flores, G., 735 (MEXU, XAL).

García, A., 1443 (FCME, MEXU).

García, I., 6240 (CIMI).

Gómez, S., s. n. (MEXU, XAL).

González, F., 654 (IEB, MO); 5374 (MEXU, XAL); 17025

(MEXU).

González, N., 29, 31 (IEB, MEXU, MO); 98, 105 (IEB, MEXU).

Guízar, E., 890 (ENCB, MEXU, XAL); 2306 (MEXU).

Ibarra, G., 3242 (HUMO, IEB, MEXU, XAL); 5927, 5959

(IEB, MEXU, MO).

Kruse, H., 2714 (FCME, IEB, MEXU).

Leavenworth, W. M. C, 949 (F); 1594 (F, MO).

Ludlow, B., 152 (MEXU).

Lyonnet, E., 1285 (MEXU).

Matuda, E., 27003 (MEXU); 30128 (MEXU, XAL).

Miranda, F. A., 1436 (MEXU, XAL).

Palacios, R., s. n. (ENCB, INIF, XAL).

Piedra, E. M., 144 (HUMO, XAL); 149, 328 (XAL); 329, 330,

331, 332, 333 (IEB, MEXU, XAL); 334 (MEXU, XAL); 335

(ENCB, IEB, MEXU, XAL).

Pringle, C. G., 3894, 3895 (MEXU); 13196 (F, MEXU, XAL).

Ramírez, A., 679 (HUMO).

Ramírez, D., s. n. (MEXU, XAL).

Rivera, I., 79 (MEXU, XAL).

Salazar, L., 21 (HUMO).

Soto, J. C., 1224 (MEXU, MO); 2502 (ENCB, MEXU); 7610

(IEB, MEXU).

Steinmann, V. W., 3967 (IEB).

Torres, B., 357 (FCME). 
Apéndice. Continuación

Urbina, M., s. n. (MEXU).

Valdez, A., 259, 287 (HUMO).

Vargas, A., 323 (FCME).

Vázquez, J., 4730 (MEXU, XAL).

Woronow, G., 2528 (F).

\section{Ficus pringlei}

Ibarra, G., 5962 (IEB).

Leavenworth, W. M. C., 1511, 1626, 1682, 1691 (F, MO); 1830 (F).

Ramírez, D., s. n. (MEXU).

Soto, J. C., 1711 (MEXU); 2457 (ENCB, MEXU, XAL); 9234

(IEB, MEXU); 9270 (FCME, MEXU, XAL); 9488 (IEB).

Torres, R., 1538 (IEB, MEXU).

Zepeda, H., 4802, 4807 (EBUM).

\section{Ficus velutina}

Argüelles, E., 2033 (MEXU).

Bye, R. A., 20863 (MEXU).

Calzada, J. I., 21776 (MEXU).

Cuevas, R., 4630 (ZEA); 4869 (IEB).
Díaz, H., 3610 (IEB); 5136 (IEB, MEXU, XAL).

García, I., 4392 (CIMI); 5006 (IEB); 6571 (CIMI, IEB).

González, N., 19, 20, 22, 23, 34 (IEB, MEXU, MO); 97, 134 (IEB, MEXU).

Hinton, G. B., 3254 (F, MO); $6214(\mathrm{~F})$.

Labat, J. N., 948 (ENCB).

Leavenworth, W. M. C., 1010, 1034 (MO).

Madrigal, X., 3303, 4155 (EBUM, IEB); 4161, 4688 (EBUM).

Matuda, E., 27023, 29203, 30852, 31894 (MEXU);

28357 (MO).

Medina, R., 415 (MEXU).

Miranda, F. A., 1589, 1912 (MEXU).

Piedra, E. M., 130 (HUMO, MEXU, XAL).

Ramírez, D., s. n. (MEXU).

Reyes, J., 2267 (MEXU).

Schiede, G., 30 (MO).

Soto, J. C., 4213 (HUMO, IEB, MEXU); 5562 (MEXU, MO); 7331 (IEB, MEXU); 12620 (MEXU).

Torres, R., 13100 (ENCB, IEB).

Viola, W., 8 (MEXU).

Zamudio, S., 2904 (IEB). 